\title{
Balkanologie
}

Balkanologie Revue d'études pluridisciplinaires

Vol. $15 n^{\circ} 1 \mid 2020$

Mémoires performatives : faire des passés et des présents

\section{Albums de photographies et mémoire du communisme en Albanie}

Books of photographs and memory of socialism in Albania

\section{Gilles de Rapper}

\section{OpenEdition}

\section{Journals}

Édition électronique

URL : https://journals.openedition.org/balkanologie/2485

DOI : $10.4000 /$ balkanologie.2485

ISSN : 1965-0582

Éditeur

Association française d'études sur les Balkans (Afebalk)

Référence électronique

Gilles de Rapper, «Albums de photographies et mémoire du communisme en Albanie », Balkanologie [En ligne], Vol. 15 n 1 | 2020, mis en ligne le 01 juin 2020, consulté le 05 août 2021. URL : http:// journals.openedition.org/balkanologie/2485; DOI : https://doi.org/10.4000/balkanologie.2485

Ce document a été généré automatiquement le 5 août 2021

(c) Tous droits réservés 


\title{
Albums de photographies et mémoire du communisme en Albanie
}

\author{
Books of photographs and memory of socialism in Albania
}

\section{Gilles de Rapper}

1 La photographie est communément créditée d'une relation forte avec la mémoire. Elle aurait la capacité, en enregistrant de façon exhaustive et fidèle une image de la réalité, d'arrêter le temps et de permettre la contemplation, dans le présent, d'une image du passé. De là, entre autres, les pratiques de photographie souvenir et la fonction largement attestée de support de la remémoration. À l'heure où la «mémoire du communisme» en Albanie devient l'objet de l'attention des chercheurs, comme le montre la multiplication des manifestations et des publications sur ce thème ${ }^{1}$, il peut sembler opportun de poser la question du rôle de la photographie dans la remémoration de la période communiste ou, en d'autres termes, de réfléchir à la façon dont les images photographiques produites à cette époque sont utilisées dans des pratiques et des discours mémoriels contemporains. La production photographique de la période communiste a en effet été massive et, pour ainsi dire, « totalitaire » : loin de se limiter à la propagande politique, à laquelle on l'associe presque naturellement, elle couvrait de nombreux aspects de l'existence et cela selon des modalités différentes. Cette période a ainsi vu la popularisation de la photographie de famille, jusqu'alors principalement réservée aux élites urbaines; elle a rendu possibles des entreprises de documentation photographique sans précédent, qu'il s'agisse d'architecture et d'urbanisme, d'ethnographie ou d'archéologie; elle a servi à tenir la chronique des activités politiques, économiques, sportives ou culturelles à travers le pays; elle a enfin donné lieu à des recherches esthétiques visant à sa reconnaissance en tant qu'art. Beaucoup de ces photographies ont été détruites, soit pendant la période communiste, soit depuis, volontairement ou accidentellement. Néanmoins, elles sont nombreuses à être parvenues jusqu'à nous, dans des archives institutionnelles comme dans des fonds privés. 
2 La question que l'on peut poser quant à leur rôle dans la remémoration de la période communiste est double. D'abord, en quoi ces images constituent-elles une mémoire de la période communiste? Quels éléments transmettent-elles de ce qui a été le présent de l'Albanie communiste, sous quelles formes et avec quelles intentions? Ensuite, en quoi ces photographies constituent-elles un support de la remémoration dans l'Albanie contemporaine? Quelles sont aujourd'hui les modalités de réception de ces images? Seul le premier aspect nous retiendra ici et nous proposons de lui appliquer la notion de mémoire performative. Par mémoire performative, nous entendons le fait que l'effet de l'acte de rappel ne consiste pas seulement en la re-présentation d'un contenu mémoriel, mais se fait sentir au-delà, dans le présent de la remémoration. Cette dernière, selon la façon dont elle est encadrée, suscitée ou provoquée, peut être utilisée ou instrumentalisée pour agir sur le présent, rejoignant ainsi la catégorie plus générale des « usages du passé ». En l'occurrence, on peut avancer que les photographies de la période communiste en Albanie, dans la mesure où elles sont un support à la remémoration, sont susceptibles d'être sollicitées dans des pratiques mémorielles relevant des mémoires performatives. Pour cela, nous commencerons par établir qu'il existe dans l'Albanie d'aujourd'hui une ou des «scènes" sur lesquelles les photographies de la période communiste sont données à voir et constituent de ce fait, non seulement un support à la remémoration, mais les éléments d'un discours sur la mémoire du communisme (une métamémoire au sens de Joël Candau ${ }^{2}$ ) et sur le présent de l'Albanie. Nous regarderons ainsi, dans le détail, deux albums publiés ces dernières années qui mettent en scène des photographies produites pendant la période communiste. Nous pourrons alors poser la question de ce que ces albums font aux images de la période communiste : quelle signification prennent-elles à cette occasion, quel contenu mémoriel réactualisent-elles et partagent-elles? Enfin, nous chercherons à montrer en quoi ces albums constituent, dans le présent, un discours sur le passé et un discours sur la mémoire ou une métamémoire.

3 Une telle approche n'épuise pas la question des relations entre photographie et mémoire qui font, depuis une vingtaine d'années, l'objet d'une attention croissante. Des travaux d'horizons disciplinaires variés permettent d'aller au-delà de la seule affirmation d'un lien particulièrement fort entre photographie et mémoire ${ }^{3}$. Ces travaux privilégient cependant les contextes occidentaux et postcoloniaux et, à quelques exceptions près, ne concernent guère le monde communiste ${ }^{4}$. L'objectif de cet article est donc aussi, à partir d'exemples concrets issus d'un moment photographique particulier, de montrer comment interagissent les photographies et les pratiques mémorielles.

\section{La mise en scène des photographies de la période communiste}

4 L'utilisation publique de photographies pour susciter le rappel de la période communiste sur un mode collectif ne date pas d'aujourd'hui. Dès les années1990, le Musée historique national avait présenté une salle consacrée à la période communiste et à ses crimes, dans laquelle étaient notamment exposées des photographies de procès, d'exécutions, de travaux forcés ou d'emprisonnement. La télévision diffusait pareillement des images dénonçant la violence ou l'absurdité du régime d'Enver Hoxha. Quant à la presse écrite, on pouvait y lire des témoignages ou des documents d'archives 
révélant les travers du régime et illustrés de photographies de l'époque. D'autres images furent publiées dans les innombrables ouvrages d'érudition locale retraçant l'histoire d'un village, d'une région ou d'une famille. Comparées aux premières, ces images servaient moins à dénoncer et à critiquer qu'à illustrer ce qu'avait été l'existence à l'époque communiste. Plus récemment, des artistes ont pu s'inspirer de photographies de cette époque ou les détourner. Avec l'émergence du passé communiste et de la mémoire du communisme dans l'espace public de l'Albanie contemporaine, d'autres mises en scène de photographies voient le jour, comme, par exemple, l'exposition proposée en 2017 par le nouveau musée de la photographie de Shkodër sur la falsification des photographies, qui comportait une section sur l'époque communiste. Enfin, on a vu paraître ces dernières années deux albums de photographies principalement consacrés à la période communiste, fait nouveau, venant rompre avec la tendance de l'histoire de la photographie albanaise à se concentrer sur la période précédant la Seconde Guerre mondiale et la prise de pouvoir par les communistes. Ces deux albums, différents à bien des égards, nous serviront à examiner le rôle de la photographie dans la remémoration de la période communiste et à tester l'hypothèse des mémoires performatives. Il convient, dans un premier temps, de les présenter et de tenter de préciser en quoi ils constituent des entreprises mémorielles.

\section{Un album d'auteur : Petrit Kumi, 2013}

5 Le premier est un album publié en 2013 à Tirana par le photographe Petrit Kumi (né en 1930) sous le titre La vie à travers l'objectif. Photographies et notes (fig. 1). Il s'agit d'une sélection de quelque 325 photographies tirées des archives personnelles de l'auteur (qu'il estime à 400000 clichés, p. 248). L'ouvrage est le résultat d'un long processus et fait suite à plusieurs expositions organisées par le photographe à Tirana $(2009,2011)$ dont certaines visaient, par la vente des tirages exposés, à financer la publication de l'album. D'un format de $24 \times 28 \mathrm{~cm}$, il est imprimé à Tirana, en noir et blanc, par un éditeur généraliste qui a déjà publié d'autres livres sur la photographie. Petrit Kumi est une grande figure de la photographie albanaise de la seconde moitié du $\mathrm{xx}^{\mathrm{e}}$ siècle. Peintre et graphiste de formation, il fait ses débuts en tant que photographe à l'Agence télégraphique albanaise (ATSH) en 1959 pour seconder les photoreporters chargés de couvrir la visite en Albanie de Nikita Khrouchtchev. Il devient, en 1964, le photoreporter de la revue Ylli, mensuel illustré faisant une large place à la photographie. Il y reste jusqu'en 1985 (plus longtemps qu'aucun autre photoreporter de la revue, avant ou après lui) pour rejoindre l'Agence télégraphique, cette fois en tant que chef du laboratoire photographique. C'est alors un poste de pouvoir : l'ATSH est le principal producteur de photographie et, depuis 1980, son laboratoire voit passer toutes les photographies produites par les photoreporters des différents médias ${ }^{6}$. Ses moyens techniques et financiers sont considérables. Après la fin de la dictature, Petrit Kumi ouvre un studio privé à Tirana, entreprise familiale qui existe encore aujourd'hui. C'est un personnage influent et respecté dans la profession, mis à l'honneur, dans les années 2000, lors des rencontres d'anciens photographes de la période communiste et fréquemment sollicité par les médias?. 
Fig. 1. Couverture de l'album de Petrit Kumi (2013)

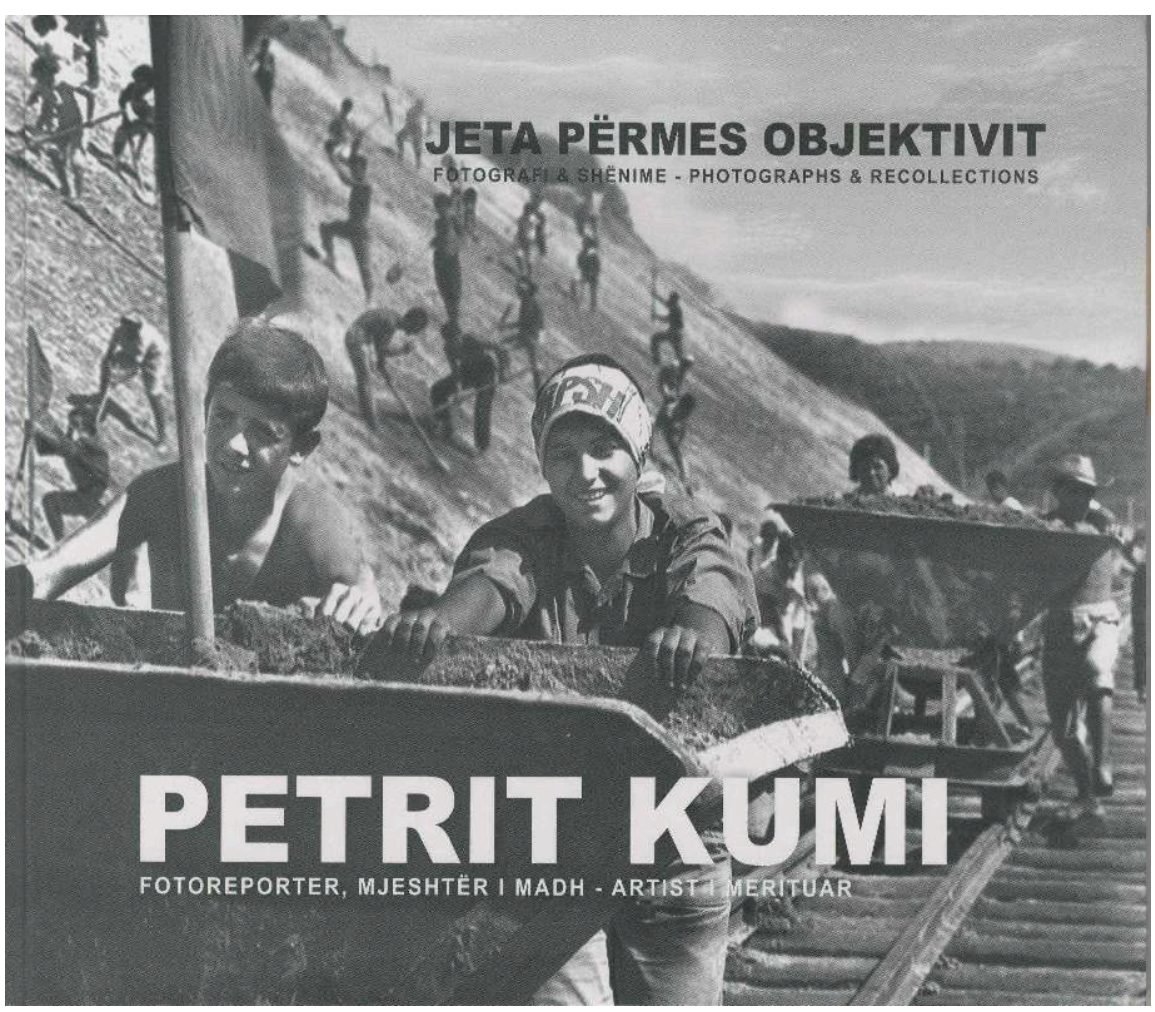

6 Pour l'essentiel, les photographies publiées dans cet album ont été prises pendant la période communiste; elles sont datées de 1945 à 1991, un petit nombre d'entre elles ayant été réalisées après 1991. La plupart sont datées et légendées, sans qu'il soit toujours possible de dire s'il s'agit de légendes de l'époque ou plus récentes. Certaines font l'objet d'un commentaire plus détaillé à destination du public d'aujourd'hui. Elles sont toutes reproduites en noir et blanc, alors même que certains des tirages exposés étaient en couleur, et pour la plupart en pleine page. Elles semblent être organisées en chapitres, mais ces chapitres sont eux-mêmes très hétéroclites : celui intitulé "Les débuts" rassemble certes des images des années 1950 et 1960, mais aussi des années 1970 et 1980, et ce qui semble faire son unité est plutôt la thématique urbaine : on y voit des vues de Tirana et d'autres villes d'Albanie, notamment des rues et des bâtiments qui ont disparu pendant la période communiste. Le chapitre suivant est intitulé «La vie. Les enfants. Mère Térésa. La médecine. Le travail volontaire. Les actions de la jeunesse. Le village » et traite effectivement de tous ces thèmes dans une progression difficile à saisir. Le troisième et dernier est du même type : « Amis célèbres, art, culture, littérature, travailleurs, politique, paysage albanais, Kosovo, sport ». Dans chaque chapitre, des textes écrits par Petrit Kumi évoquent des souvenirs plus précis : la visite de Mère Térésa en Albanie, en 1989, le dernier portrait officiel d'Enver Hoxha, une rencontre avec l'écrivain Ismaïl Kadaré ou avec le photographe Kristaq Sotiri. L'ensemble de ces textes, comme les légendes des photographies, sont publiés simultanément en albanais et dans une traduction anglaise.

7 L'album entretient ainsi plusieurs types de relations à la mémoire. Il est d'abord l'occasion pour l'auteur de faire part de ses souvenirs personnels, notamment dans les textes dont nous venons de parler. On peut penser que certaines photographies fonctionnent ici comme catalyseurs d'une métamémoire, c'est-à-dire d'une mémoire 
mise en scène. La prégnance du travail photographique dans la mémoire de l'auteur est annoncée dès le premier texte introductif : «Le travail créatif dans la chambre obscure, le développement des négatifs et de la photographie dans les bacs resteront pour moi un souvenir marquant tout au long de ma carrière de photographe, une expérience extraordinaire qui ne se répètera jamais, unique en son genre» (p. 4). La volonté de transmettre, par les photographies, les souvenirs d'une époque révolue est manifeste dans certains commentaires accompagnant les images. Dans le deuxième chapitre, les photographies représentant les "actions" (aksion), à savoir les campagnes de travail bénévole et obligatoire effectuées par les lycéens et les étudiants, sont suivies par un texte, imprimé en lettres capitales, enjoignant le lecteur à prendre connaissance du "sacrifice» (sakrificë) de ces jeunes gens pendant la dictature, à le respecter et à « ne jamais oublier le passé de notre pays » (të mos harrohet asnjë herë e kaluara e vendit tonë) (p. 53). L'inclusion, au fil des chapitres, de photographies récentes représentant enfants, neveux et petits-enfants de l'auteur, associées, dans la mise en page, à des photographies d'enfants et de jeunes gens de la période communiste, a ainsi pour effet de provoquer l'implication ou l'engagement émotionnel des premiers et de leurs contemporains (fig. 2) : c'est une injonction à un «devoir de mémoire», comme si les images du bonheur actuel ne devaient pas faire oublier les souffrances passées. Cependant, en matière de "sacrifice", les images reproduites, conformément aux injonctions de l'époque, présentent, elles aussi, exclusivement des images de bonheur, principalement de bonheur au travail et dans la camaraderie. Le décalage entre ces images de liesse et ces visages souriants, d'une part, et la réalité à laquelle ils font référence, d'autre part, semble donc assumé, comme si ces images de bonheur devaient notoirement être lues comme des images de « sacrifice » et de souffrances. En troisième lieu, la sélection des photographies et certains des textes qui les accompagnent manifestent la capacité de la photographie (et du photographe) à "fixer» (fiksoj), "enregistrer» (regjistroj), "(re)présenter» (paraqis) les transformations et les évolutions du pays et à en "être témoin» (jam dëshmitar; toutes ces expressions figurent dans le texte introductif de la page 7). L'ensemble de l'album se présente ainsi comme porteur d'une valeur documentaire et d'archivage: il constitue une "mémoire » de la période communiste, un moyen de rappeler ce que fut la vie à cette époque. Force est pourtant de constater la rareté du vocabulaire relatif à la mémoire ou à l'oubli : deux ou trois occurrences à peine pour l'ensemble de l'album. Dans les textes, ce n'est pas la relation entre photographie et mémoire qui est mise en avant, mais plutôt celle entre photographie et réalité. Les trois "préfaces » sont ainsi traversées par la tension entre photographie comme enregistrement fidèle mais mécanique de la réalité et photographie comme art, c'est-à-dire comme impliquant les choix et la sensibilité du photographe. La première est un texte de l'écrivain Dhimitër Shuteriqi (1915-2003), dont un portrait figure en page 81 de l'album, écrit en 1985 en réponse à une demande de Petrit Kumi (p. 8-9). Les deux autres sont écrites par des amis de l'auteur à l'occasion de la publication de l'album : l'une, signée par le sculpteur Thoma Thomai, est intitulée "Artiste et journaliste » (p. 10) ; l'autre, du géologue Kadri Gjata, s'intitule « Respect pour l'homme» (p. 11). 
Fig. 2a. Élèves de l'école du village d'Andon Poçi, Gjirokastër, 1973

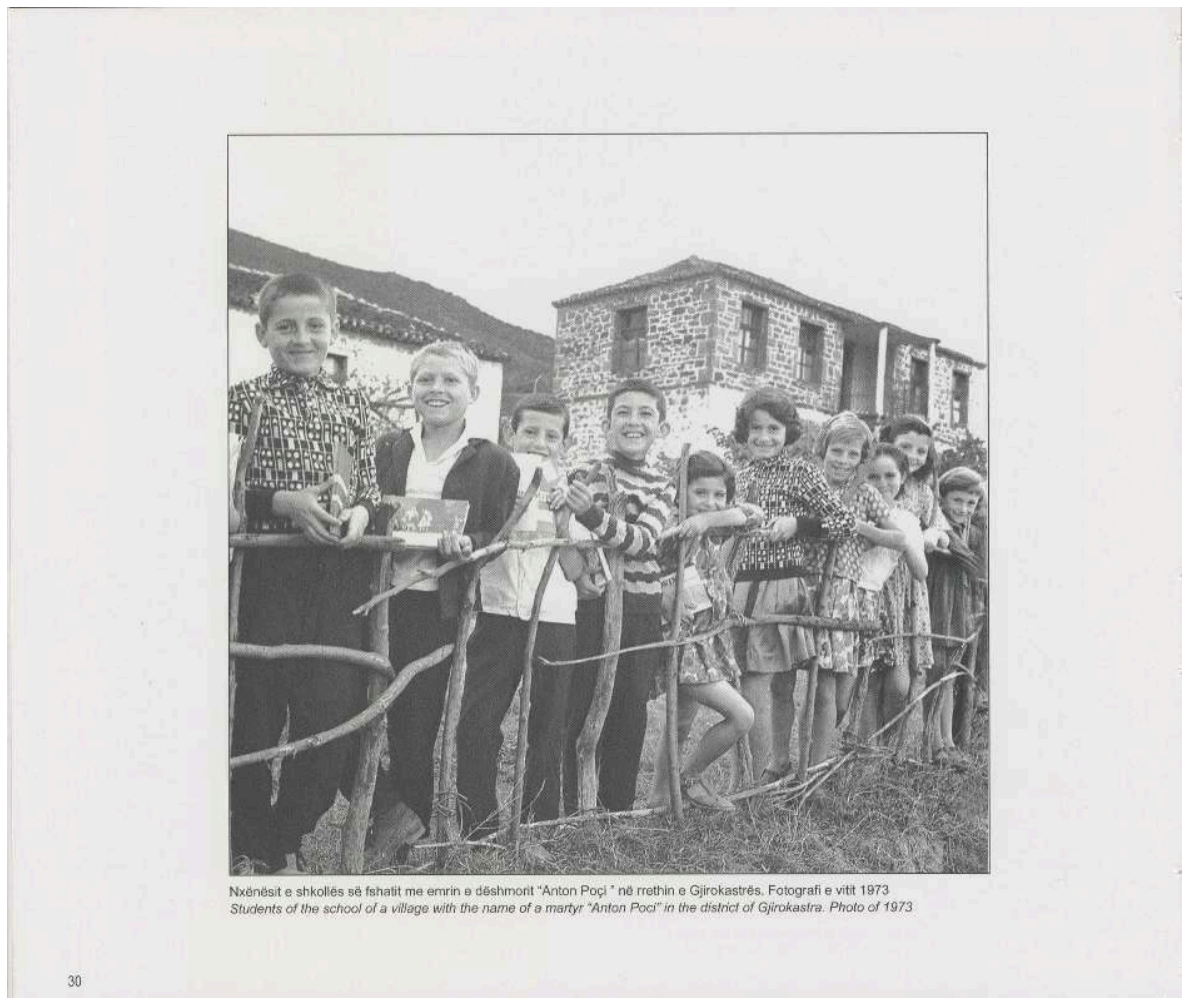

Kumi, 2013, p. 30

Fig. 2b. Petites-filles de l'auteur, 2012

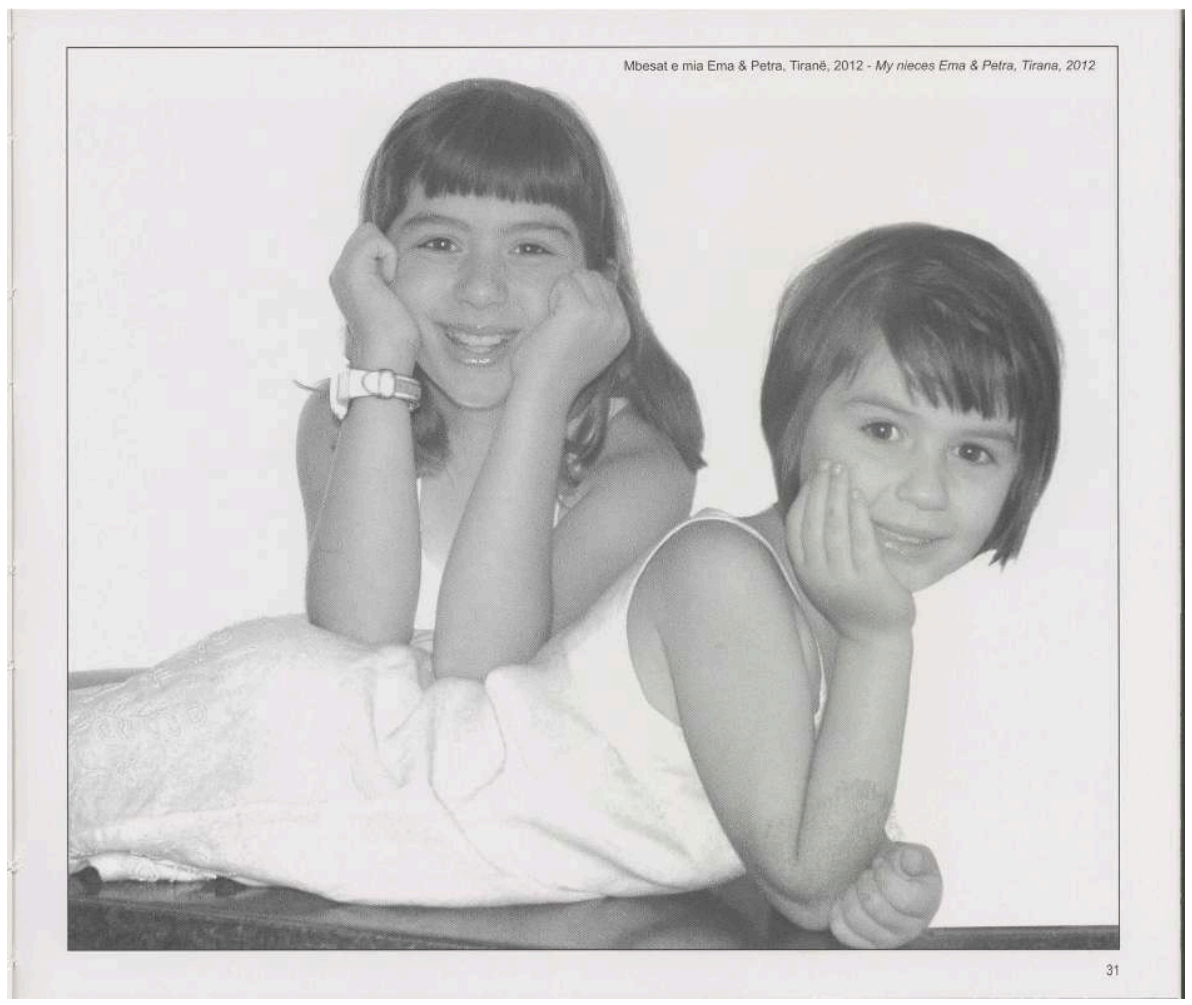

Kumi, 2013, p. 31 


\section{La photographie de service public : Safet et Gjylzade Dokle, 2014}

Le deuxième album, publié en 2014, est consacré à un couple de photographes, Safet et Gjylzade Dokle (fig. 3) ${ }^{8}$. Les différences avec l'album de Petrit Kumi sont nombreuses : l'initiative ne revient pas ici aux photographes eux-mêmes, décédés, mais à l'un de leurs fils et à un parent plus lointain, tous deux étrangers à la profession. Contrairement à Petrit Kumi, appartenant à la catégorie des "photographes d'institutions ", Safet (1923-1981) et Gjylzade (1923-1996) Dokle était photographes locaux dans une ville de province du nord-est de l'Albanie, Kukës. Leurs conditions de travail et leur production en étaient très différentes. Safet, photographe amateur dès les années 1930, obtient, en 1951, l'autorisation de pratiquer la photographie de manière professionnelle et privée. À cette époque, des ateliers coopératifs de photographes sont créés dans tout le pays et l'activité privée, en dehors des coopératives, n'est possible que contre le paiement de taxes. Gjylzade, initiée à la photographie par son mari, rejoint la coopérative des photographes de Kukës en 1955. En 1966, les deux époux créent, au sein de ce qui est désormais l'entreprise étatique communale, le studio photographique «Kosova», qui réunit les photographes de la ville.

Fig. 3. Couverture de l'album Dokle (2014)

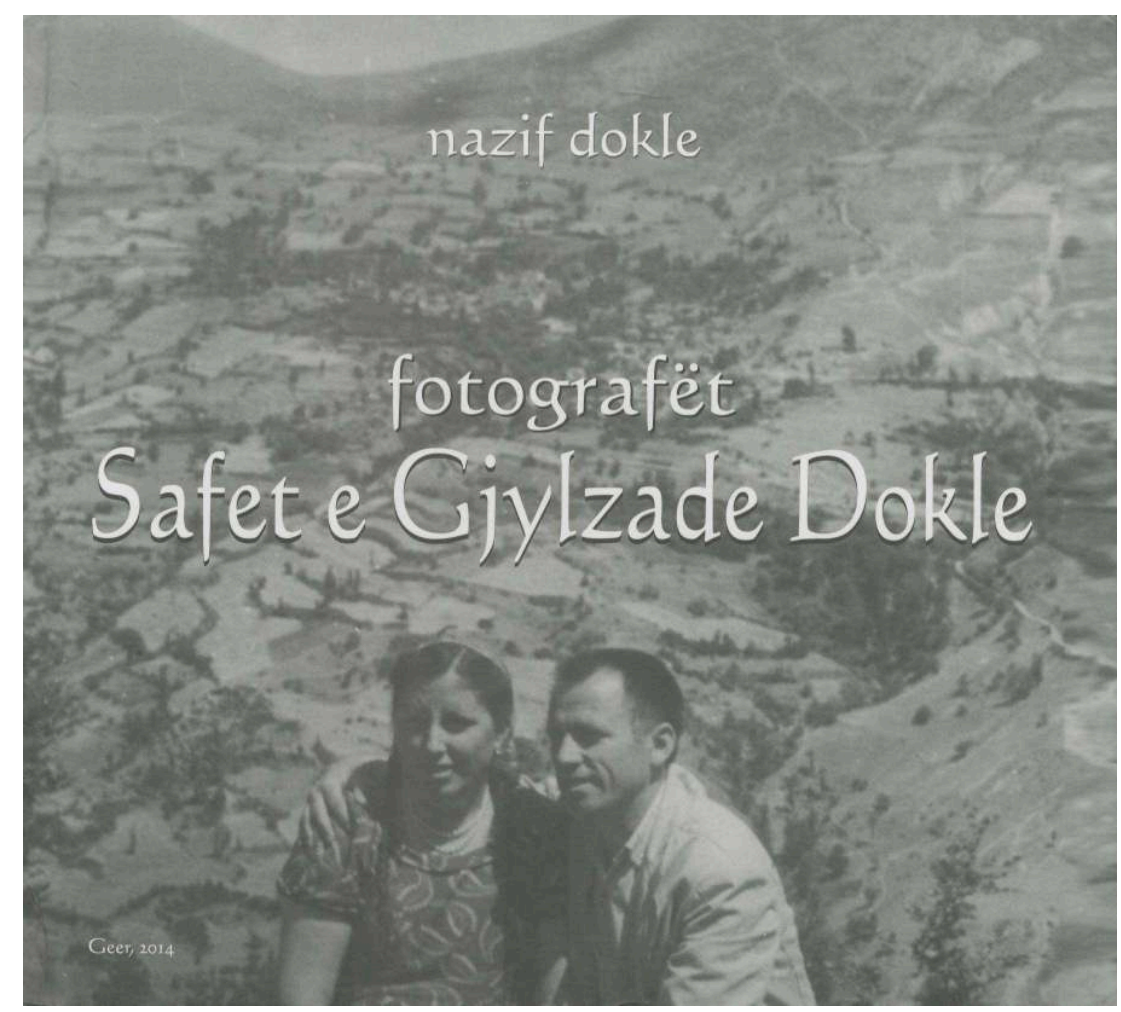

La sélection publiée ne donne à voir qu'un aspect de ce qu'était la production des photographes du service public dans les petites villes: ces professionnels devaient d'abord répondre aux besoins en photographie de la population (photographie de mariage, photographie souvenir, photographie d'identité) et des institutions locales. Mais ils étaient aussi chargés de documenter la "construction du socialisme " au niveau local: ils étaient présents lors des activités politiques (meetings, élections, 
commémorations et inaugurations), culturelles et sportives. Ils devaient aussi documenter toutes les activités économiques, notamment lorsqu'elles témoignaient de l'industrialisation ou de la modernisation de l'agriculture. C'est cette fonction de documentation qui est seule présentée dans l'album, à quelques exceptions près. Pour les mêmes raisons, alors que l'album de Petrit Kumi concerne l'échelle nationale (et même au-delà, puisqu'il rapporte aussi un reportage effectué au Kosovo à l'été 1981, p. 158-163), celui des époux Dokle est avant tout local : il porte essentiellement sur la ville de Kukës et ses environs, notamment sur le village d'origine des deux photographes, Borje. Paradoxalement, mais conformément à la politique de l'époque, la position frontalière de ce village et du district de Kukës avec la province yougoslave du Kosovo n'est pas même mentionnée. Seules de rares photographies consacrées aux unités de gardes-frontières rappellent cette position (p. 41, 56). De même, la période couverte est beaucoup plus restreinte que chez Petrit Kumi: si de nombreuses photographies remontent aux années 1940, rares sont celles qui vont au-delà de l'année 1970. Cette date correspond au départ à la retraite de Gjylzade et, vraisemblablement, à un ralentissement de l'activité du couple. Il se peut aussi que le passage du système de la coopérative à celui de l'entreprise d'État ait changé leurs conditions de travail.

D'autres traits distinguent les deux albums. Comme cela se passe souvent avec la littérature d'érudition régionale, la diffusion de l'album des Dokle, imprimé lui aussi à Tirana, à 300 exemplaires, se fait par réseaux de connaissances plus que par la vente en librairie. L'un des responsables du volume précise bien que la publication est d'abord destinée "aux proches, aux amis et aux camarades de [ses] parents » et ensuite aux autres personnes intéressées (p.4). De plus, il s'agit moins d'un portrait personnel à travers l'œuvre photographique que d'une tentative de montrer l'étendue et la richesse de la production du couple de photographes. Les photographies reproduites dans l'album sont beaucoup plus nombreuses que celles de l'album de Petrit Kumi (1 100 sur un fonds estimé à 22000 clichés) et, de ce fait, d'un format réduit. Chaque page, d'un format légèrement plus petit que celui de l'album de Kumi, comprend entre 4 et 10 photographies (fig. 4). Elles sont toutes légendées et le plus souvent datées, informations extraites des registres mêmes tenus par les photographes. 
Fig. 4. Aspects de la vie économique : «1. Vendeur de pâtisseries ambulant (1938) ; 2 . Distribution d'aide (1954) ; 3. Confiseur privé (1959) ; 4. Atelier de séchage de prunes (1960); 5 . Magasin d'alimentation (1959)»

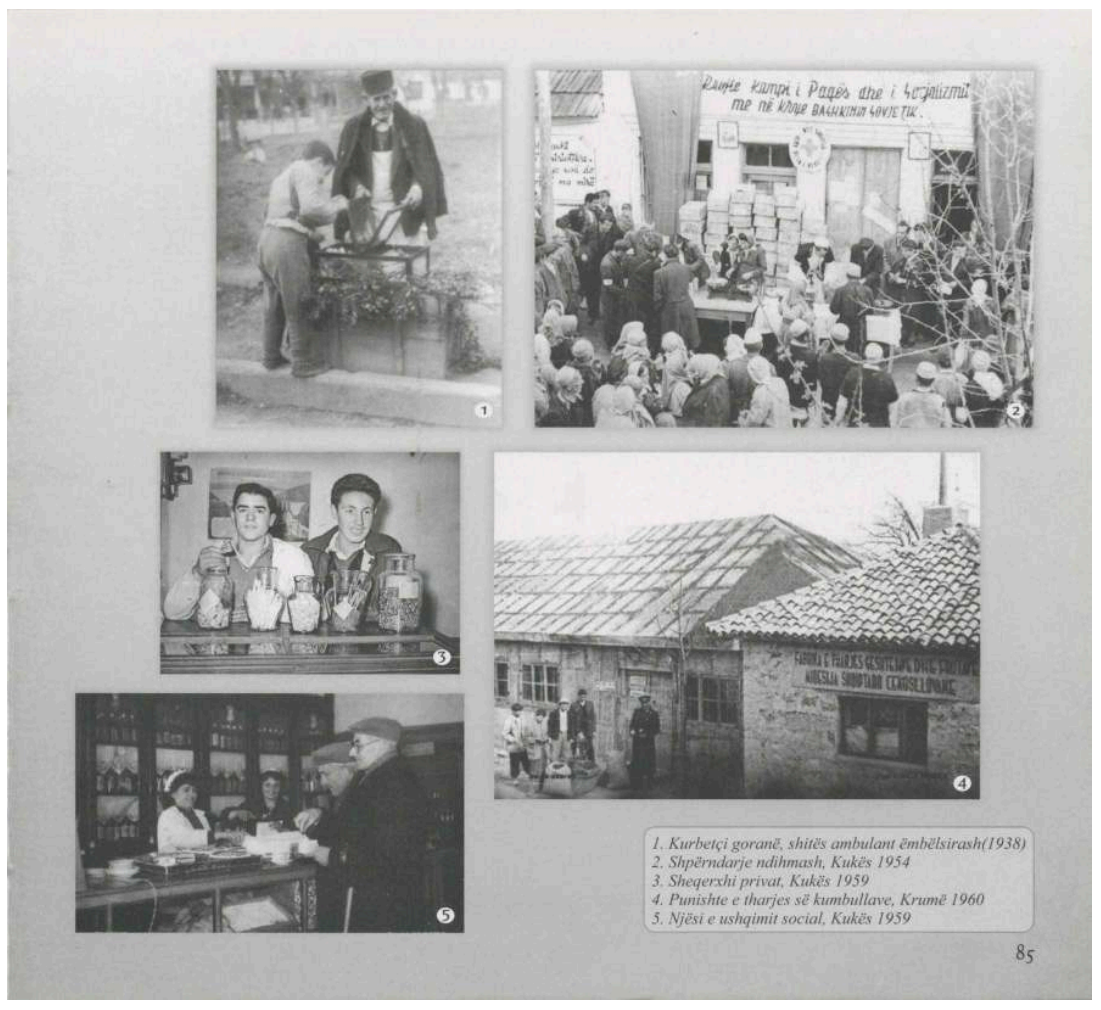

Dokle, 2014, p. 85

11 Sur le plan formel, les images sont beaucoup moins variées que celles de Petrit Kumi. Dans leur très grande majorité, il s'agit de plans larges montrant des groupes impliqués dans des activités collectives: rassemblements et cérémonies politiques, activités sportives ou agricoles, photographies de classe. Les portraits individuels, très nombreux chez Petrit Kumi, sont beaucoup plus rares ici, et les gros plans inexistants. Si de nombreuses photographies sont posées, elles le sont de façon très simple, sans recherche esthétique dans l'organisation des plans. On peut comparer ici une photographie prise par Petrit Kumi sur le marché de Kukës en 1961 (p. 102) (fig. 5) aux images de la "vie économique " produites par les époux Dokle dans la même ville et à la même époque. Contrairement à ces dernières, la photographie de Petrit Kumi n'est pas qu'informative ; par sa composition et par la pose de l'homme au premier plan, elle participe à la fabrication de l'image de l'Albanie du Nord vue depuis Tirana en portant un regard simultanément critique et amusé sur l'orientation "patriarcale » de ces régions : confortablement appuyé contre un mur, l'homme fume rêveusement sa pipe tandis que s'avance une femme chargée de paquets. Le jeune homme amusé sur la droite, à moitié coupé par le bord de la photographie, introduit de la distance et rappelle le caractère composé et mis en scène de l'image. 


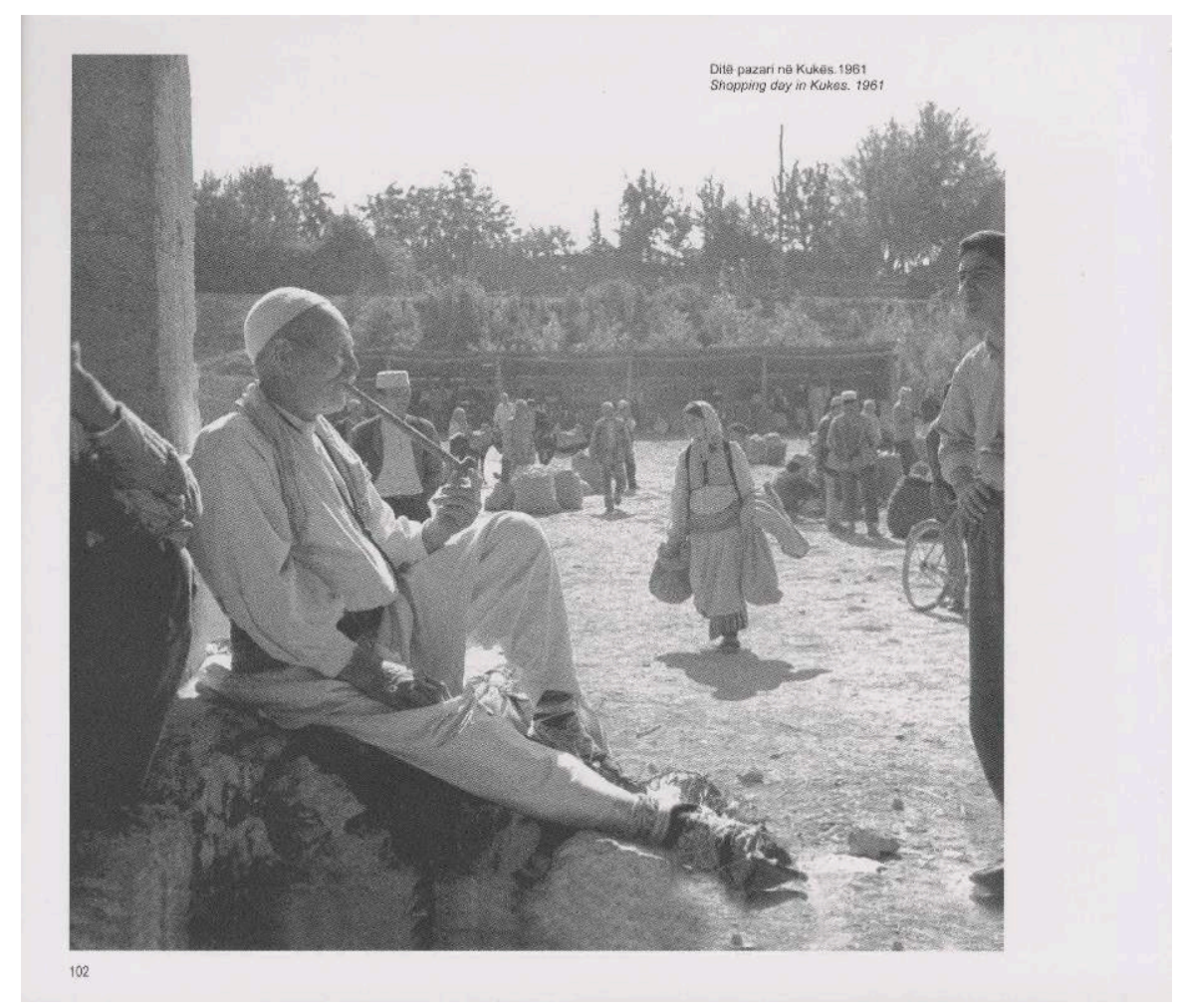

Kumi, 2013, p. 102

Enfin, l'organisation en chapitres de l'album Dokle est à la fois beaucoup plus rigoureuse et conventionnelle : chaque chapitre est thématique et le plan, rappelé dans une table des matières en fin de volume, absente chez Kumi, reprend les grandes rubriques qui organisaient par exemple les musées locaux et les histoires villageoises conçus pendant la période communiste. La progression est la suivante: après un premier chapitre biographique, dans lequel sont reproduites des photographies personnelles et familiales des époux Dokle remontant aux années 1930, ainsi que des images récentes des appareils utilisés par les photographes et des classeurs renfermant leurs archives, les chapitres thématiques traitent de la ville de Kukës et de son environnement, de la chronique de la vie politique, des activités économiques, du système scolaire, de la vie artistique et culturelle, des activités sportives, du système de santé et d'ethnographie. Un dernier chapitre offre une sélection plus restreinte, présentée comme relevant de "l'art de la photographie » (arti i fotografisë). Dans la plupart des chapitres, la présentation des photographies suit un ordre chronologique, ce qui n'est pas le cas dans l'album de Petrit Kumi. Chaque chapitre est introduit par un court texte des éditeurs insistant sur la valeur documentaire et mémorielle du fonds. L'ensemble de l'album est de même introduit par un texte situant les deux photographes et leur production dans l'histoire de la photographie de la région et rappelant les grandes étapes de la constitution et de la transmission de leurs archives.

Le lien entre cet album et la mémoire est ainsi différent. La dimension personnelle passe pour ainsi dire au second plan: les photographies publiées ne sont pas un prétexte à l'évocation de souvenirs personnels, ni de la part des photographes, ni de la part des éditeurs. Pour autant, la publication elle-même est présentée comme une tentative de perpétuer (përjetësoj) le souvenir des deux photographes, en particulier de 
la part d'un fils qui estime avoir une dette envers ses parents (p. 5). L'album est donc une sorte de mémorial dédié à des parents qui étaient aussi photographes et qui ont de ce fait eux-mêmes laissé un matériau mémoriel. C'est un deuxième aspect de la relation entre cet album et la mémoire: les photographies sont présentées comme la manifestation de la volonté des deux photographes de «fixer» et de transmettre aux générations futures une image de ce qu'était la vie à leur époque (p.5) et de bâtir ce qui constitue pour les générations d'aujourd'hui une "mémoire photographique » (p. 102). Chaque texte introductif insiste ainsi sur la distance temporelle qui nous sépare de l'époque à laquelle les photographies ont été prises et sur le fait que ces dernières constituent un "miroir» (pasqyrë) qui donne à voir la vie telle qu'elle était alors. On connaît la métaphore du " miroir qui se souvient », appliquée très tôt à la photographie naissante en France et en Angleterre ${ }^{10}$. Elle est ici largement exploitée : ce que montrent ces images est la réalité conservée par la photographie. En ce sens, ces textes rejoignent les préfaces de l'album Kumi : les photographies publiées reflètent la réalité « de manière fidèle » (me besnikëri, p. 102), plus ou moins poignante selon les qualités du photographe. Si elle est critiquable, le photographe n'y est pour rien.

Malgré leurs différences, les deux albums ont en commun d'inviter le lecteur à regarder, plus de vingt ans après la fin de la période communiste, des photographies produites à cette époque et montrant un monde qui n'est plus. Formulé différemment dans les deux albums, l'objectif commun est bien de partager, publiquement, des images de l'Albanie communiste et d'en proposer, par la mise en page et par les textes, une interprétation destinée au spectateur contemporain. La sélection même des photographies est un acte relevant de la métamémoire, une prise de position sur ce qui convient d'être rappelé et regardé de la production des photographes. Il est donc temps de s'intéresser de plus près à ce qui est donné à voir aujourd'hui par ces images.

\section{Donner à voir la période communiste}

Même s'il est impossible ici de comparer ces deux albums à l'ensemble de la production des photographes et de déterminer de façon sûre les critères qui ont présidé à la sélection des images, on peut mettre en évidence un certain nombre de convergences et de thèmes récurrents qui donnent une idée de la façon dont ces photographies sont mobilisées aujourd'hui pour former une image de la période communiste et de ce que, inconsciemment, elles donnent à voir de cette période ${ }^{11}$. Dans ce qui suit, les textes accompagnant les photographies nous serviront à saisir les intentions, déclarées de façon plus ou moins explicite, des auteurs et leurs interprétations actuelles des images. Nous chercherons aussi à donner du sens à la succession et à la mise en page des images $^{12}$.

Dans les deux cas, l'un des objectifs affichés des auteurs est de mettre à disposition du public d'aujourd'hui des photographies d'un monde qui n'est plus. La période communiste, ou le communisme en Albanie, n'est pourtant pas, en soi, le sujet des deux albums et aucune tentative n'est faite pour la définir ou pour en faire un objet photographiable. Elle apparaît plutôt comme un arrière-plan ou comme un cadre dans lequel se déroulaient les activités représentées sur les photographies. Les titres des deux albums évitent à cet égard toute référence directe à la période communiste. Dans le titre comme dans les textes de Petrit Kumi, l'accent est mis sur la "vie ", comme si cette vie se déroulait en deçà du contexte politique et qu'elle ne reflétait 
qu'incidemment les circonstances politiques (p. 4, 7, 248). En outre, la répartition thématique des images à l'intérieur de l'album semble empêcher toute tentative de définition univoque de l'univers visuel de la période communiste. Il en est de même dans l'album Dokle, où les images les plus marquées par le contexte politique sont circonscrites dans un des premiers chapitres, intitulé « Chronique de la vie politique de Kukës » (chapitre le plus fourni de l'album, avec 50 pages), introduit par un texte qui dresse un inventaire des objets et des thèmes abordés sans chercher à caractériser la période en elle-même (p. 20). L'objectif affiché n'est donc pas de proposer, par l'intermédiaire de ces photographies, une "mémoire du communisme». Le contenu mémoriel mis en œuvre par ces albums ne peut cependant être détaché de la référence à la période communiste et cette relation nous semble revêtir trois formes.

\section{Photographes de l'Albanie communiste}

17 En premier lieu, certaines de ces images donnent à voir le travail des photographes dans les circonstances particulières de la dictature. Elles montrent ce que l'on attendait d'eux, attentes variables selon les époques et les institutions pour lesquelles ils travaillaient. Le chapitre biographique sur les époux Dokle ne manque pas de rappeler le contexte institutionnel de leur activité, qui se caractérisait par le contrôle politique exercé sur la photographie. Les photographies reproduites dans l'album montrent, par la répétition des mêmes scènes prises d'année en année sous le même angle de vue, combien la tâche de chroniqueur endossée par les photographes locaux était systématique et répétitive. Par contraste, le chapitre consacré à la photographie artistique témoigne, à défaut d'une réelle créativité, du plaisir de photographier des êtres proches et des paysages familiers comme du désir d'enregistrer et de transmettre une émotion (fig. 6). 


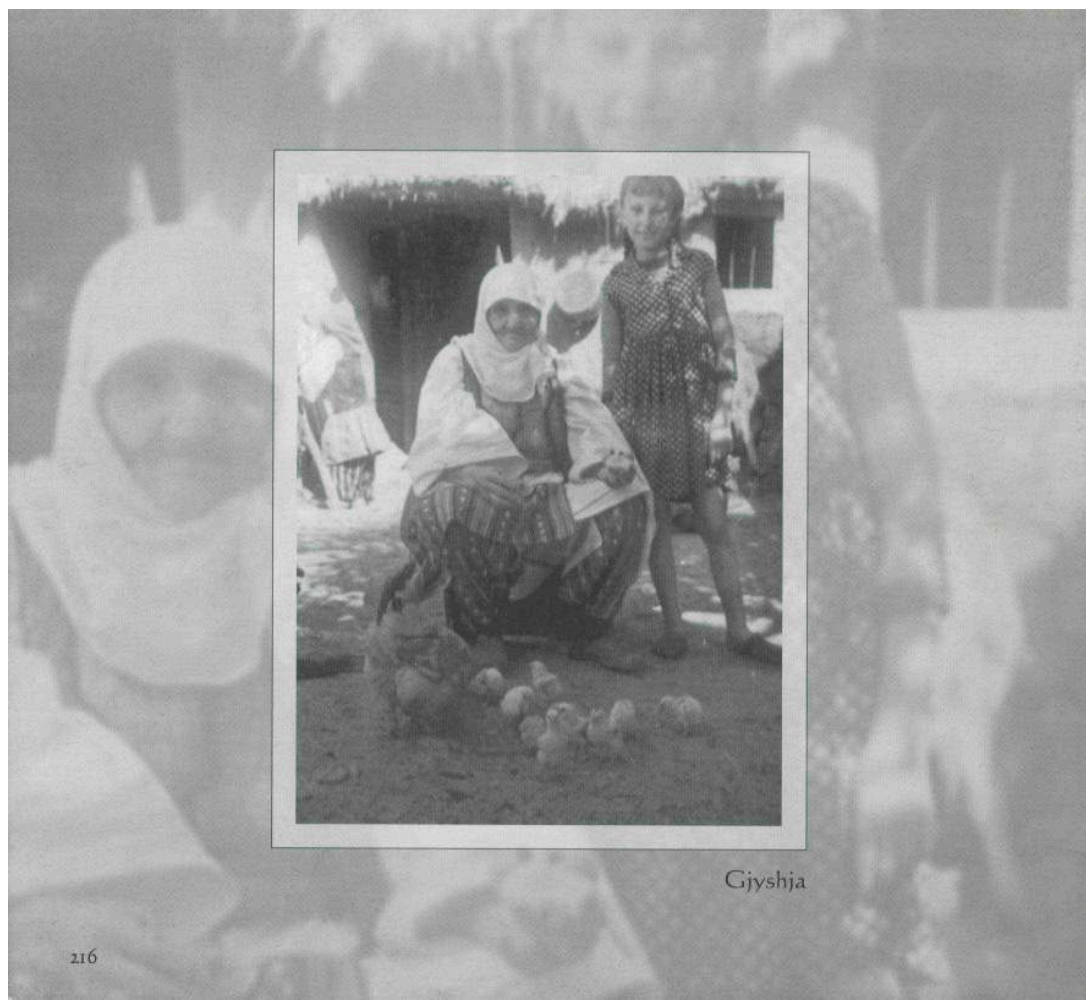

Dokle, 2014, p. 216

18 L'aspect personnel est plus prononcé dans l'album de Petrit Kumi. Un des objectifs de l'auteur est en effet de rendre compte de sa trajectoire professionnelle et de rappeler ce que sa fonction de photoreporter signifiait dans ce contexte. Certains clichés le montrent au travail, sur le terrain (p. 242-243) (fig. 7), d'autres posant avec ses modèles (p. 244-245) (fig. 8). La fabrication ou la manipulation de quelques images, en particulier lorsque le sujet est Enver Hoxha, fait l'objet d'un commentaire et d'un récit rapportant des souvenirs personnels (p. 148-149 sur le dernier portrait officiel d'Enver Hoxha, en février 1985 ; p. 154-155 sur sa dernière apparition publique, en novembre 1984 ; p. 246-247 sur la retouche, en 1970, d'une photographie de 1930 visant à supprimer toutes les personnes entourant Enver Hoxha). Enfin, plusieurs images évoquent son travail pour le magazine Ylli (p. 240-241) (fig. 9) et ses relations avec d'autres photographes professionnels, albanais ou étrangers (p.120-121, 234-235, 250-251) (fig. 10 et 11). Dans tous les cas, les textes accompagnant ces photographies ne cessent de rappeler qu'elles sont le résultat du travail du photoreporter et qu'elles ne peuvent être vues seulement comme des images, mais comme le produit d'une organisation et d'une idéologie propres à la période communiste : «Les photographies placées dans l'album sont le résultat de [ma] conception [de la photographie], mais aussi de l'époque où elles ont été réalisées » (p. 248). 
Fig. 7. «Prise de vue à l'entreprise agricole de Maliq, Korçë, 1977 »

Duke fotografuar në Ndërmarjen Bujqësore të Maliqit, Korçë, 1977

Taking photos in the Agricultural Enterprise of Maliq, Korça, 1977

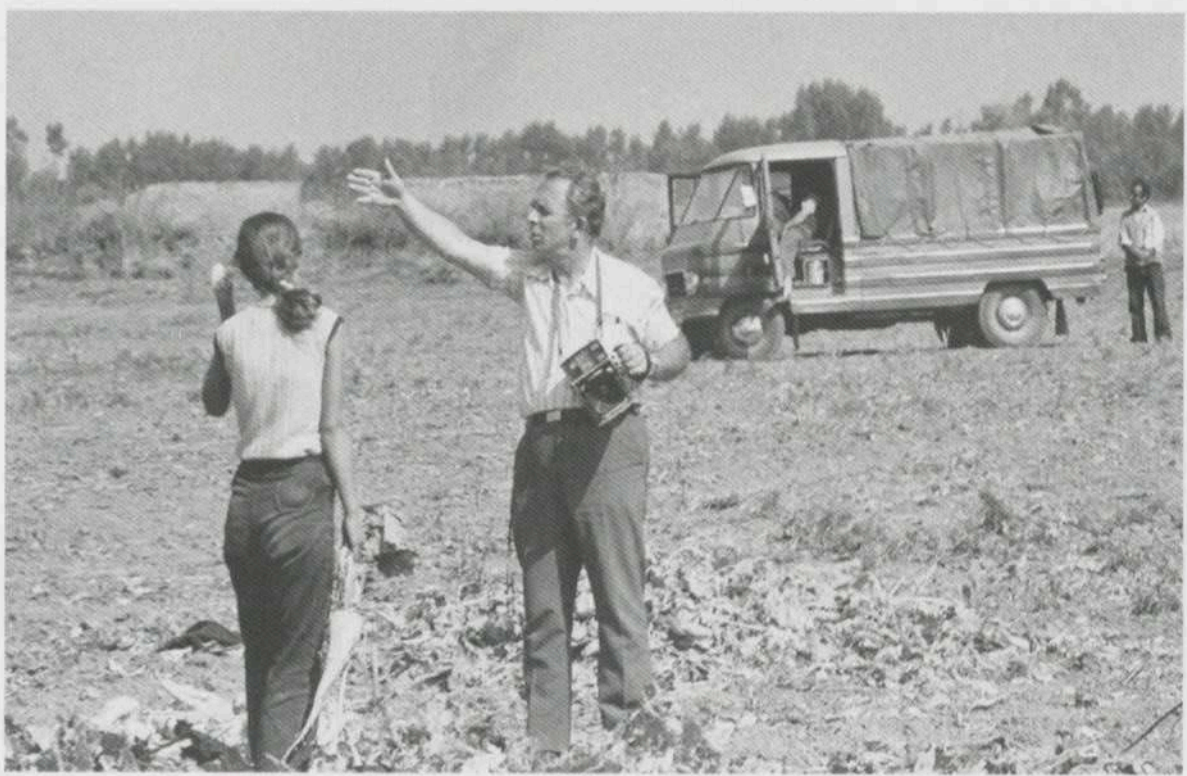

Kumi, 2013, p. 243

Fig. 8. «Dans le studio du grand écrivain de littérature albanaise moderne, Ismail Kadare, 1981 » et "Après une conversation avec le grand peintre albanais Ibrahim Kodra, 1971 »

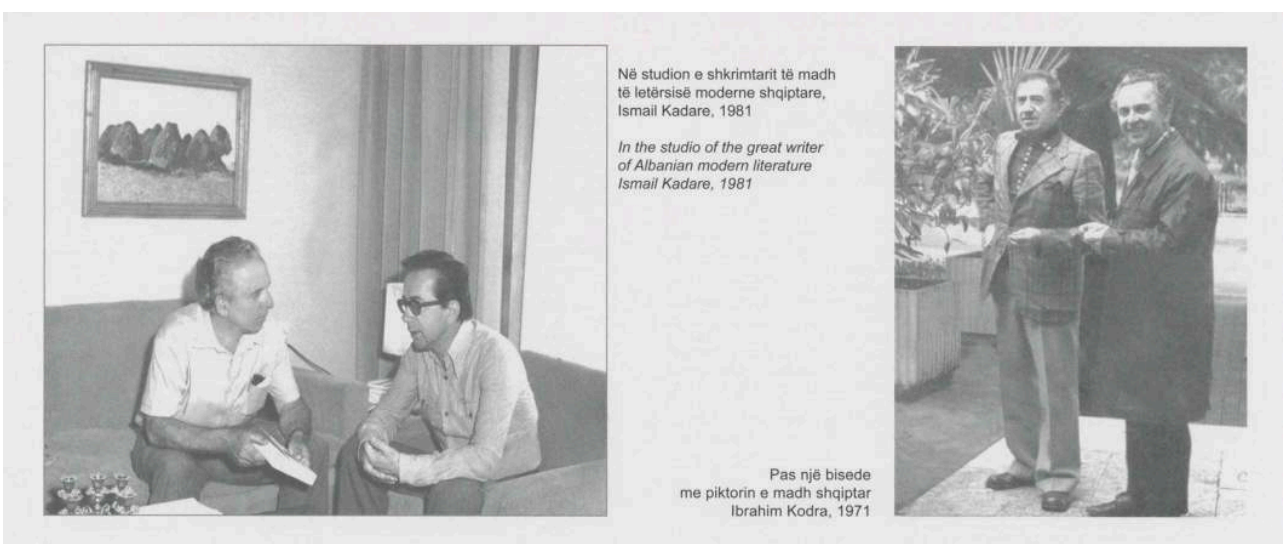

Kumi, 2013, p. 245 
Fig. 9. « Le conseil de la rédaction de la revue Ylli, 1977 »

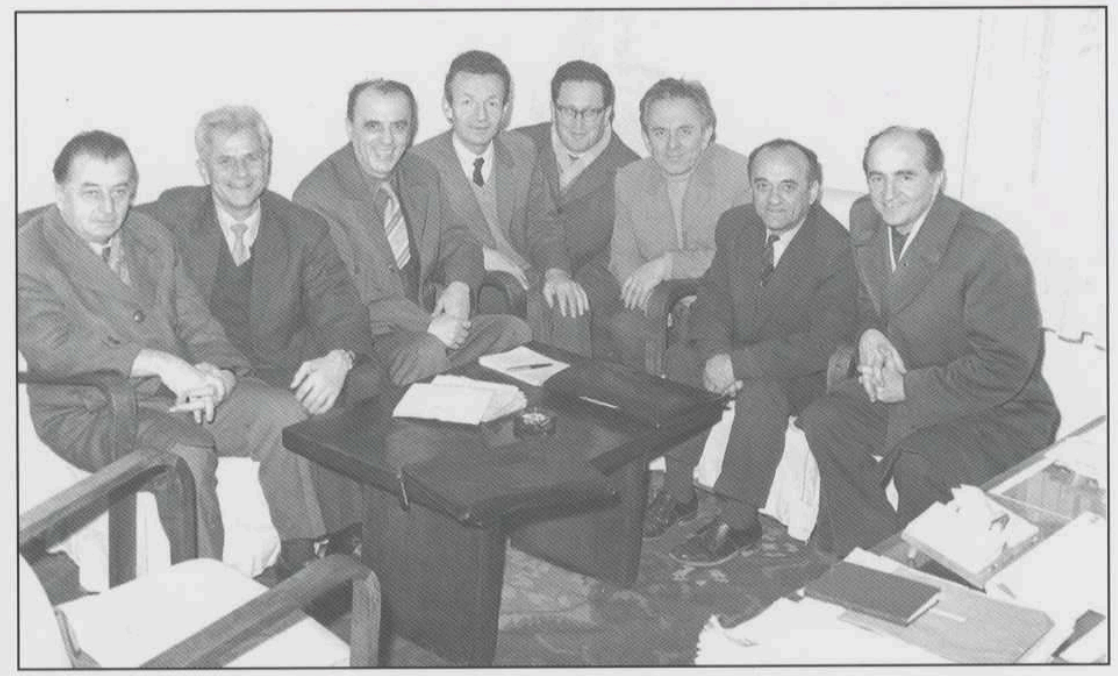

Kolegjumi i Redaksisë së revistës "YLLI" viti 1977.

Nga e majta në të djathtë: publicisti dhe kritiku i njohur letrar Myzafer Xhaxhiu, ekonomisti Shaqir Prizreni, publicisti dhe gazetari Niko Nishku, sekretar i kolegumit, gazetari dhe shkrimtari Novruz Turhani, kryeredaktor i revistës, historiani Gazmend Shpuza, fotoreporteri dhe redaktori artistik Petrit Kumi, publicisti Adem Rada, shkrimtari dhe publicisti, mjeku Jordan Haxhinikolla.

Petrit Kumi est le troisième à partir de la droite.

Kumi, 2013, p. 240

Fig. 10. « Les maîtres de la photographie albanaise, 1971 »

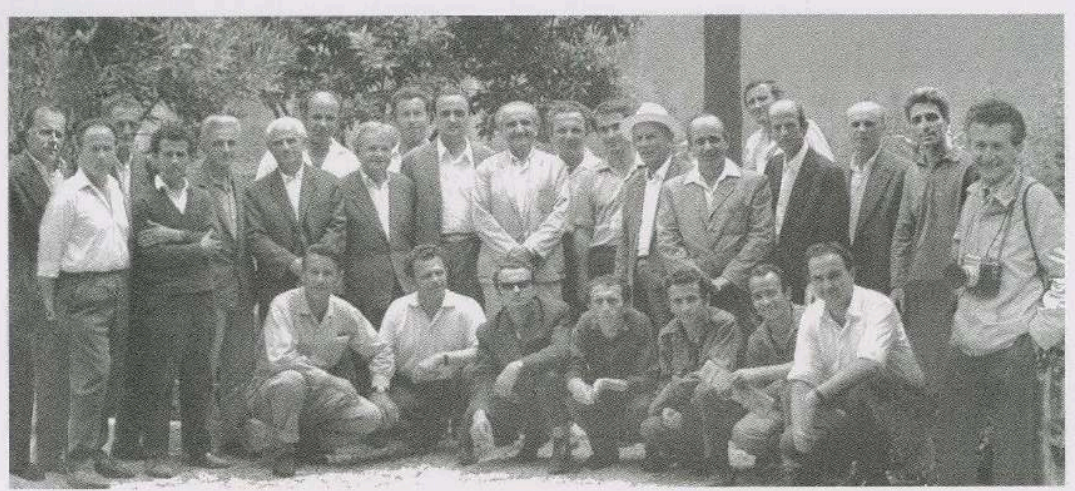

MJESHTRA TË FOTOGRAFISË SHQIPTARE, 1971

Nga e majta në këmbé:

Rrok Berisha, Mjeshtri Refik Veseli, Ymer Halili,

Foto Stamo -Piktori i Populi, Hycmet Agolli, piktor, Mieshtri Jani Ristan , Hysen Gostivari, Kujtim Buza piktor, Artisti i Merituar, Mjeshtri Vasil Ristani, Petrit Kumi, Mjeshter i Madh-Artist i Merituar

Dhimitraq Trebick pilMar Her

Nikolin Baba, Rexhep Znarta, Meksi Xhufka, Pleurat Sulo, Petrit Ristani.

234

Kumi, 2013, p. 234 
Fig. 11. Avec le photographe turc Sami Gülen

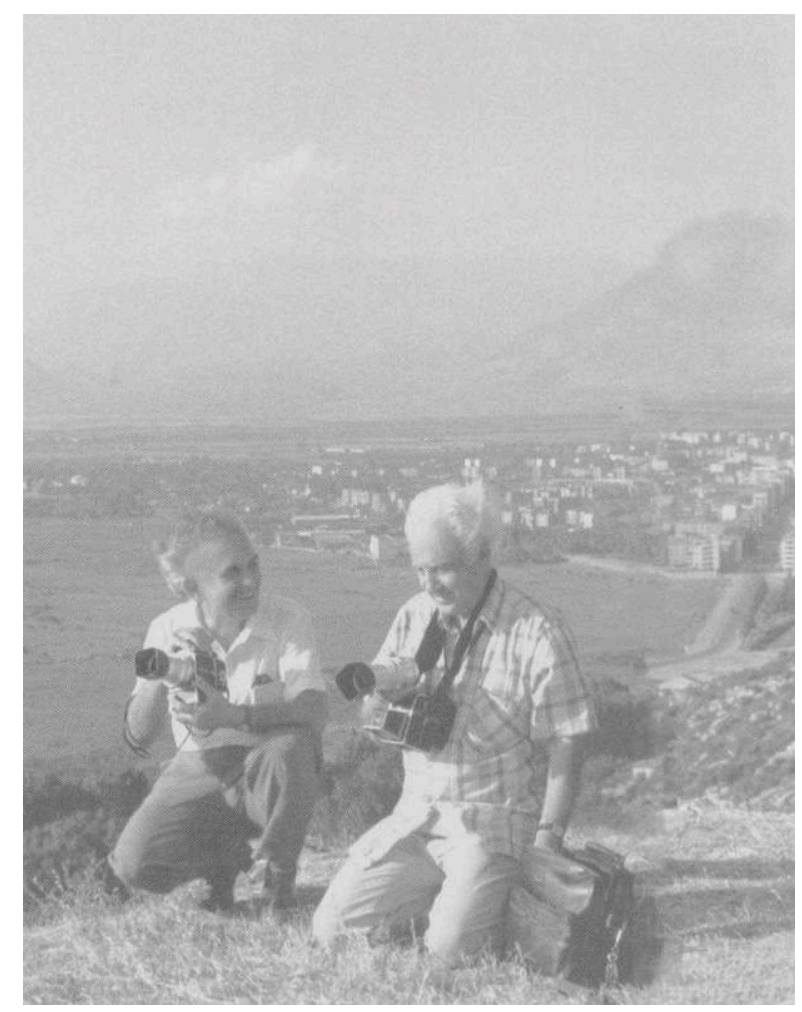

Kumi, 2013, p. 251

\section{Les cadres photographiques de la mémoire}

Ensuite, ces photographies révèlent ce que l'on pourrait appeler les «cadres photographiques de la mémoire " pour détourner l'expression de Maurice Halbwachs : pendant la période communiste, la photographie avait pour fonction, entre autres, de délimiter ce dont il fallait se souvenir et comment il fallait s'en souvenir. Deux aspects nous semblent particulièrement saillants dans les deux albums: d'une part, la photographie accompagne et rend visibles la transformation et la modernisation du pays sous la direction des communistes; d'autre part, elle exalte l'activisme et la prééminence du collectif sur l'individuel.

Concernant le premier aspect, il est remarquable que les deux albums s'ouvrent, après la présentation des photographes, sur des images de transformations urbaines. Chez Petrit Kumi, des photographies de chantiers urbains à Tirana montrent à quel point la ville a changé dès la période communiste et pas seulement, comme on l'entend souvent dire aujourd'hui, depuis la fin de la dictature. Des quartiers et des bâtiments anciens font place à des immeubles modernes, hauts de neuf étages (p. 16-17) (fig. 12) ; la place centrale change radicalement entre 1946 et 1987 à tel point qu'aucun des bâtiments visibles sur l'une des photographies ne se retrouve dans l'autre (p. 20-21) (fig. 13 et 14). 
Fig. 12. "Au croisement de la rue des Barricades et de la rue Luigj Gurakuqi, à Tirana en 1964, avant la construction des immeubles de neuf étages»

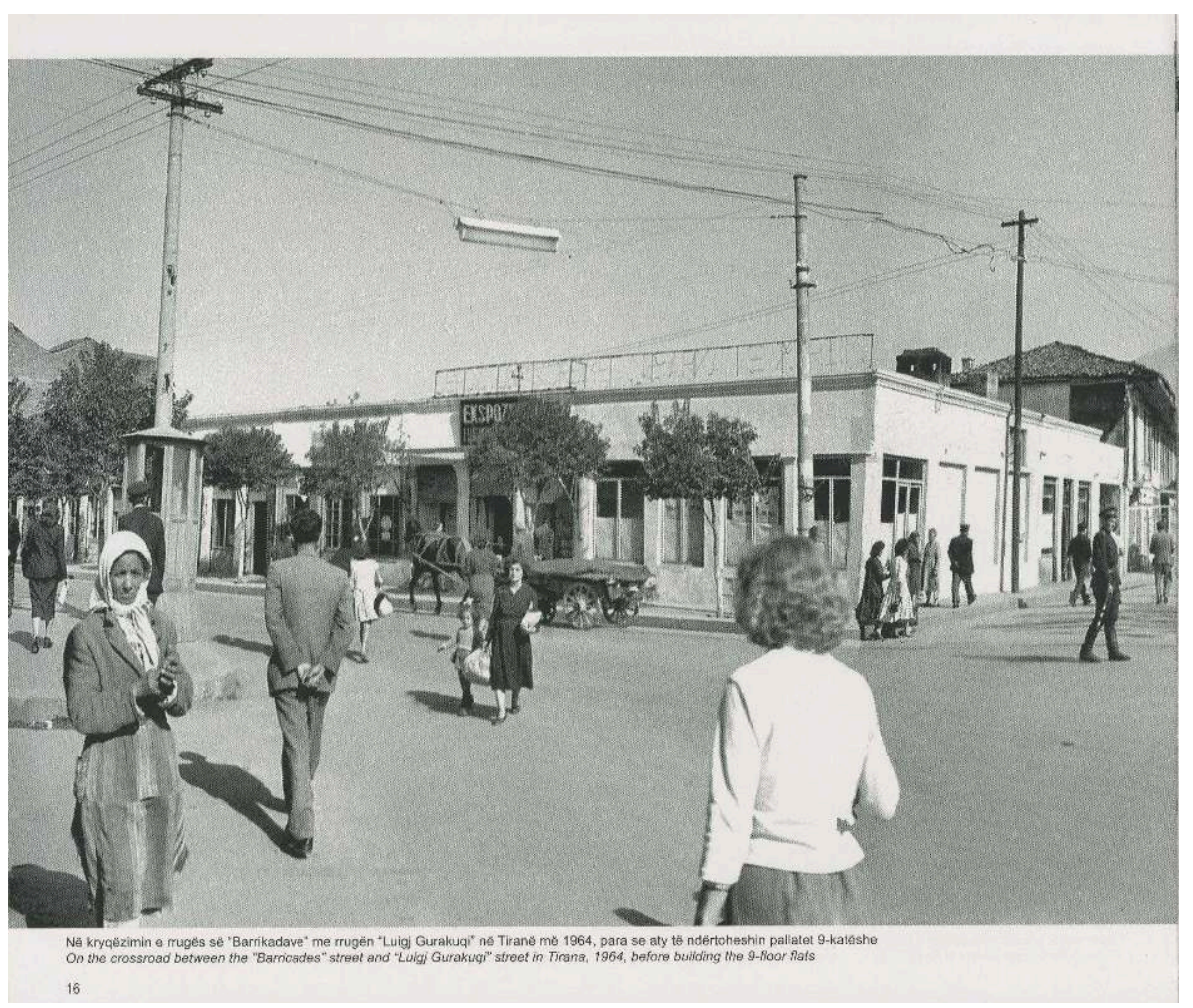

Kumi, 2013, p. 16

Fig. 13. "Vue du centre de Tirana en 1946 »

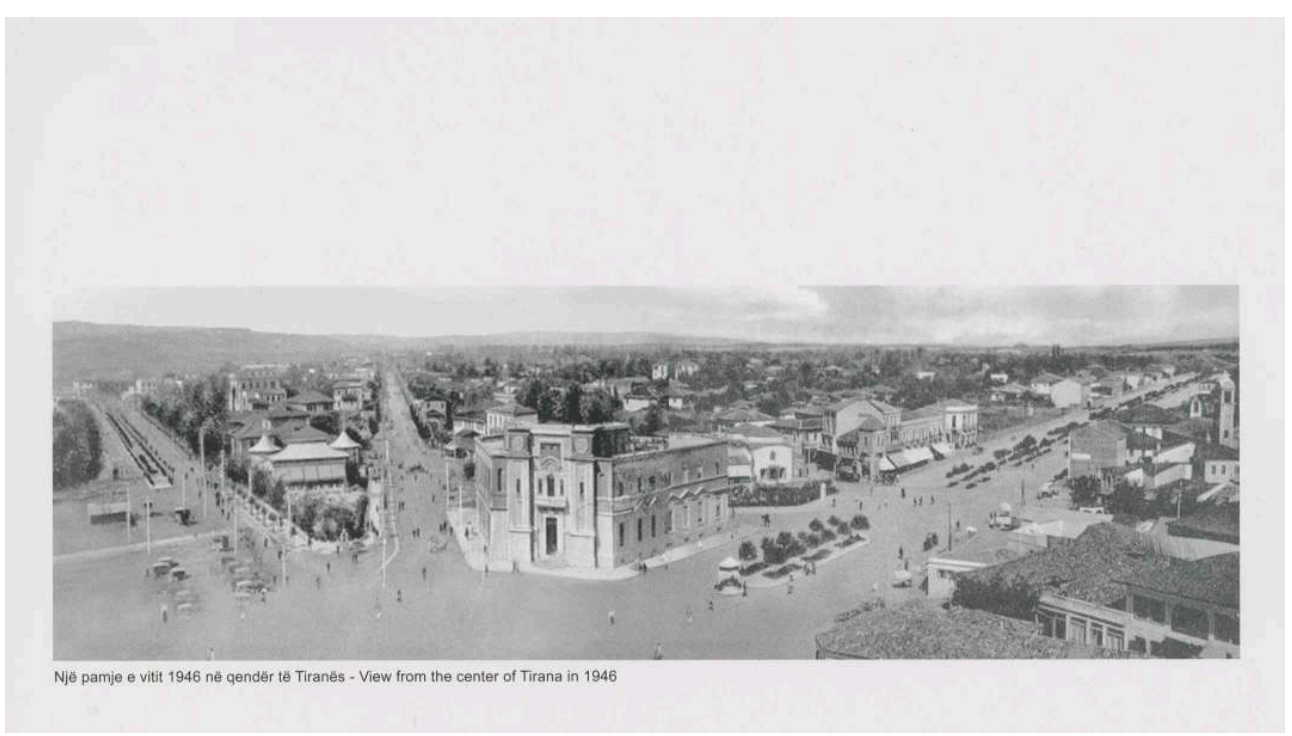

Kumi, 2013, p. 20 
Fig. 14.

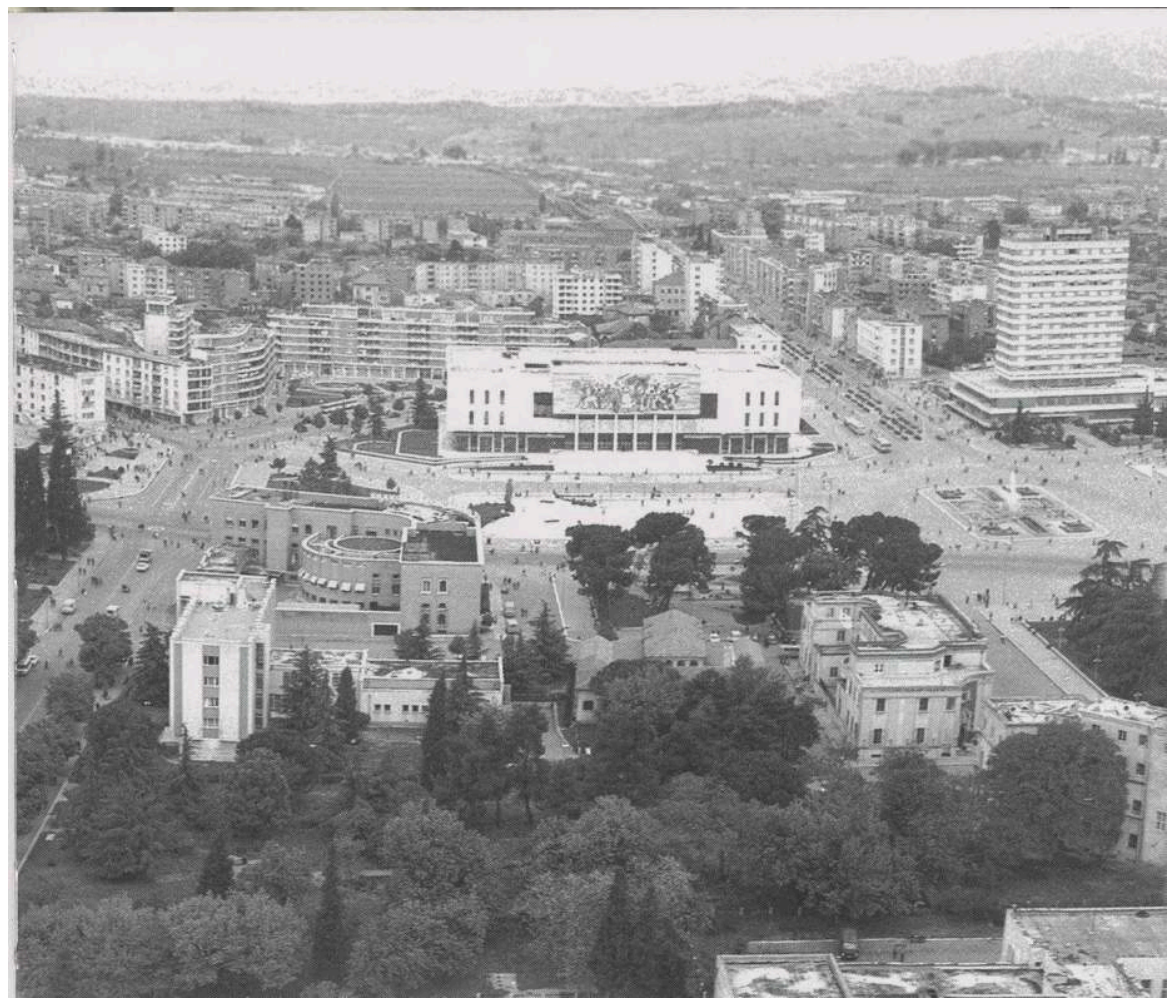

Kumi, 2013, p. 21

21 Dans l'album Dokle, le changement est encore plus dramatique : la ville de Kukës, dont un chapitre entier présente des vues prises entre les années 1923 et 1978 et qui est le décor de nombreuses images reproduites dans les autres chapitres, est engloutie en 1976 par les eaux du barrage de Fierzë et remplacée par une nouvelle Kukës bâtie à partir de 1962 sur un site voisin (fig. 15). Si, pour Paul Ricœur, « les lieux habités sont par excellence mémorables ${ }^{13}$ ", les deux albums rappellent constamment à quel point l'habitat s'est transformé pendant la période communiste : la mémoire est ici mémoire du changement. 
Fig. 15. Vues de Kukës : « 1 . Les eaux du Drin Noir submergent une partie de Kukës, $1963 ; 2$. Le Drin Noir à l'entrée de Kukës ; 3 . Kukës vu du sud-est ; $4-5$. Kukës à la veille d'être submergé par les eaux du lac de Fierzë, 1978 »

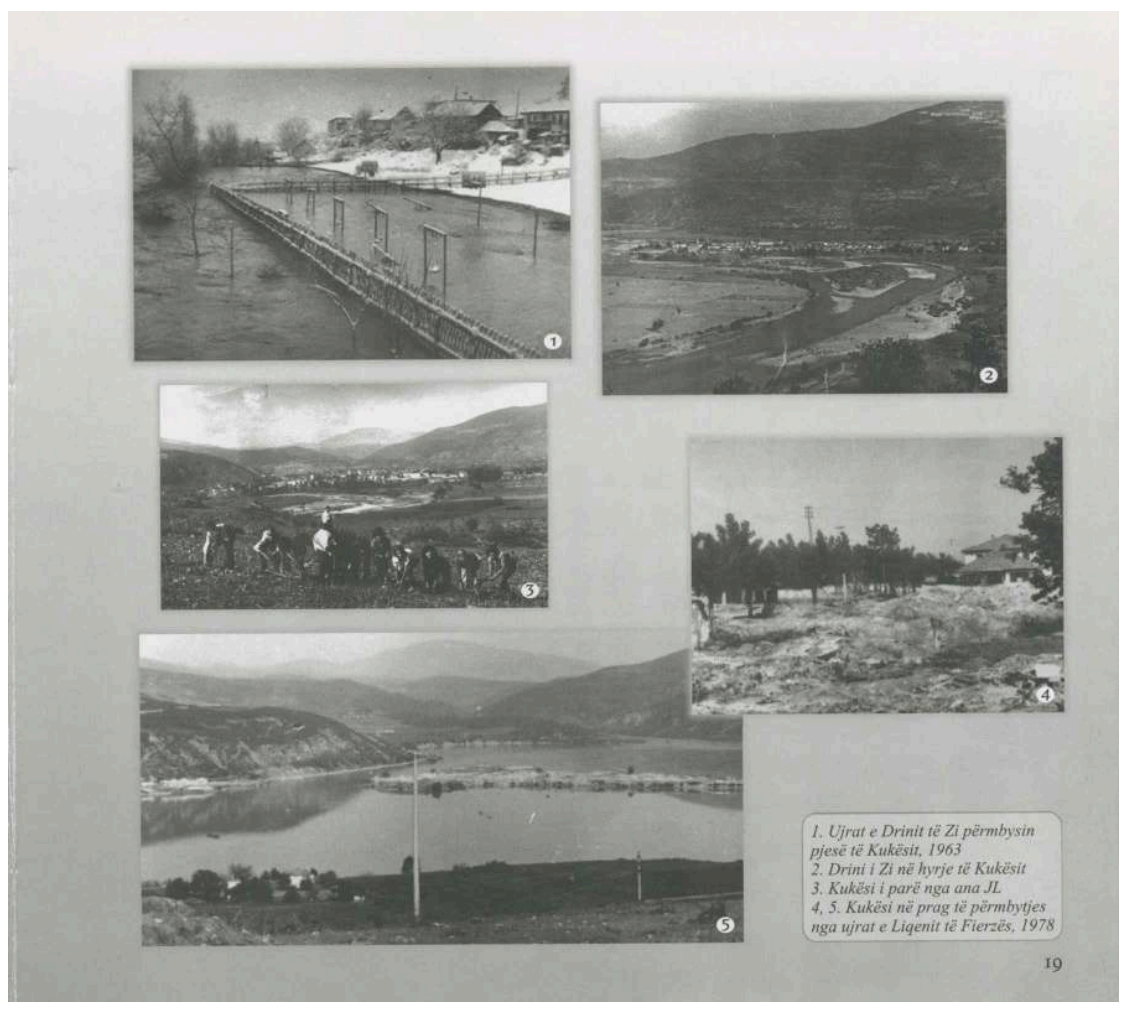

Dokle, 2014, p. 19

22 Il en va de même des occupations et des professions. Le chapitre intitulé « Miroir de la vie économique» dans l'album Dokle dresse à la fois un panorama des activités traditionnelles et un tableau des innovations : battage des céréales à la main et par une batteuse (p. 76-77) (fig. 16 et 17), labours à l'araire et arrivée du premier tracteur (p. 73, 78), apiculture «traditionnelle» et «moderne» (p. 82-83). La succession des images rend visible le passage du temps et donne une épaisseur temporelle à la période en question. On voit même, à la suite de photographies présentant les divers métiers et artisanats dans les années 1960 et 1970 (vendeur ambulant, confiseur, pâtissier, cuisinier, potier, tailleur, cordonnier, etc.), une série de neuf images qui rendent compte d'une exposition de "produits artisanaux de Kukës ", à une date non spécifiée, témoignant de la mise en scène de la tradition (p. 90) (fig. 18). 
Fig. 16. Vues de la vie économique : «1. Montage des gerbes sur les meules ; $2-3$. Battage par les chevaux ; 4. Lancer du grain à la pelle ; 5 . Battage du seigle ; 6 . Criblage du grain après le battage »

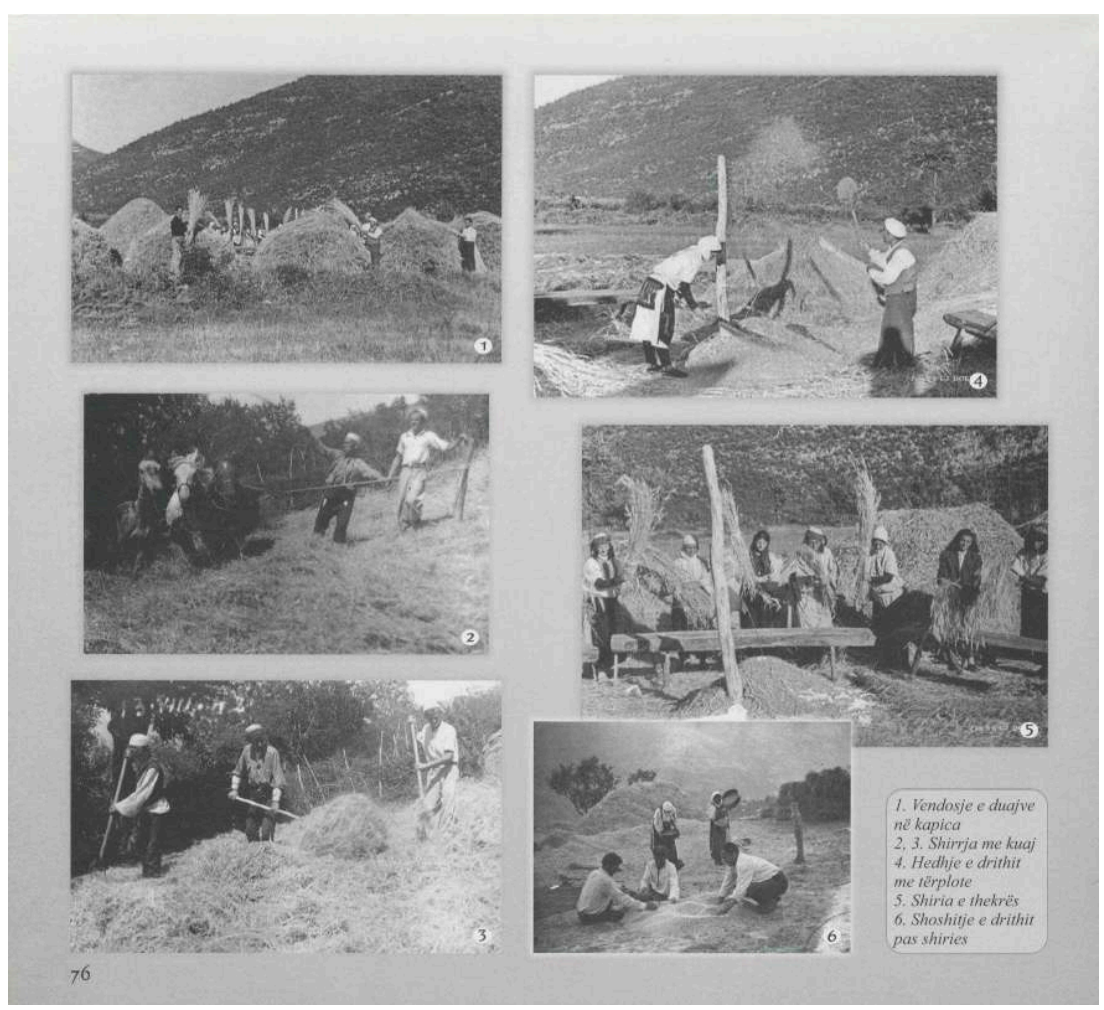

Dokle ,2014, p. 76

Fig. 17. Battage mécanique

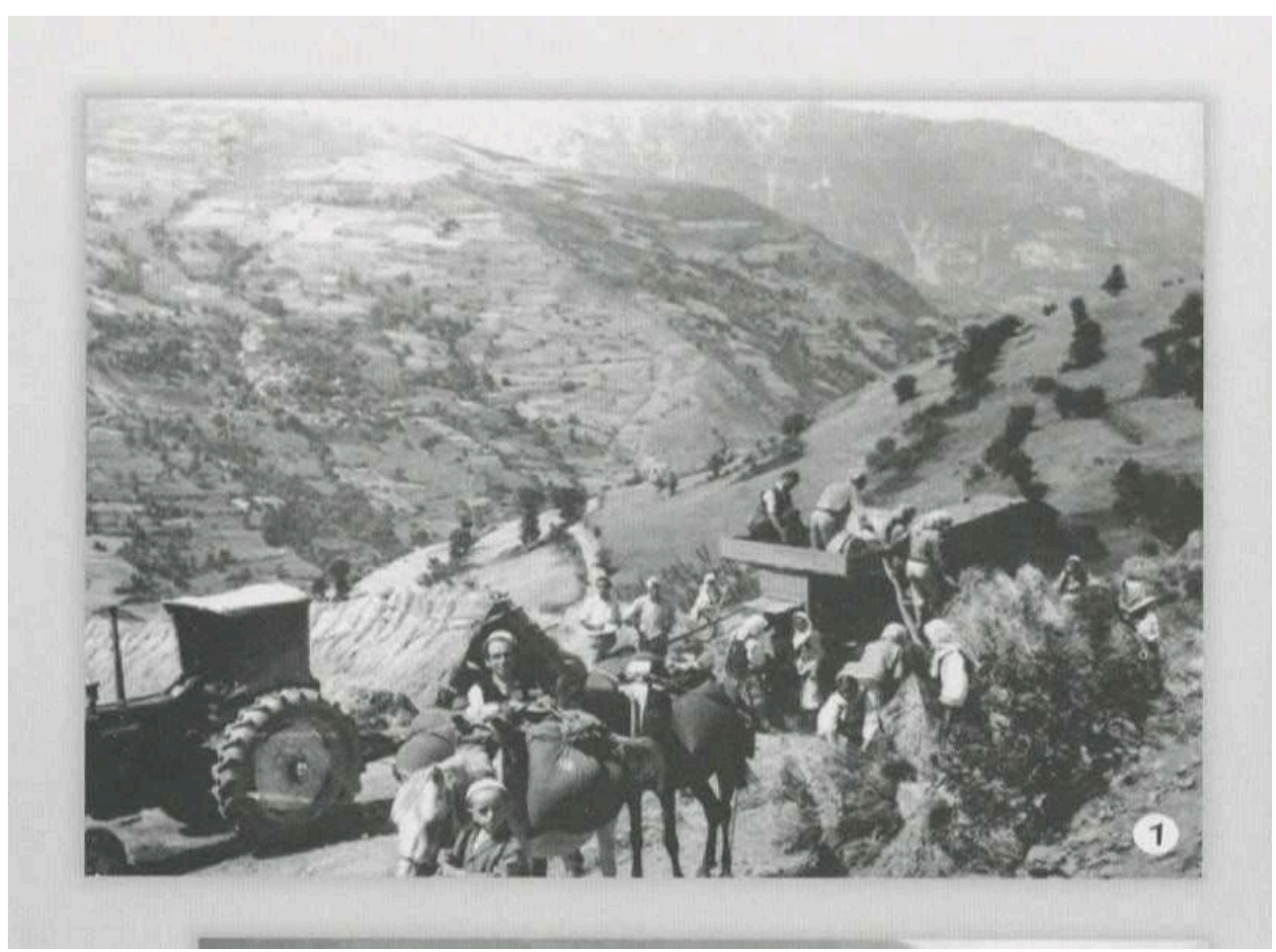

Dokle, 2014, p. 77 
Fig. 18. « Produits artisanaux de Kukës »

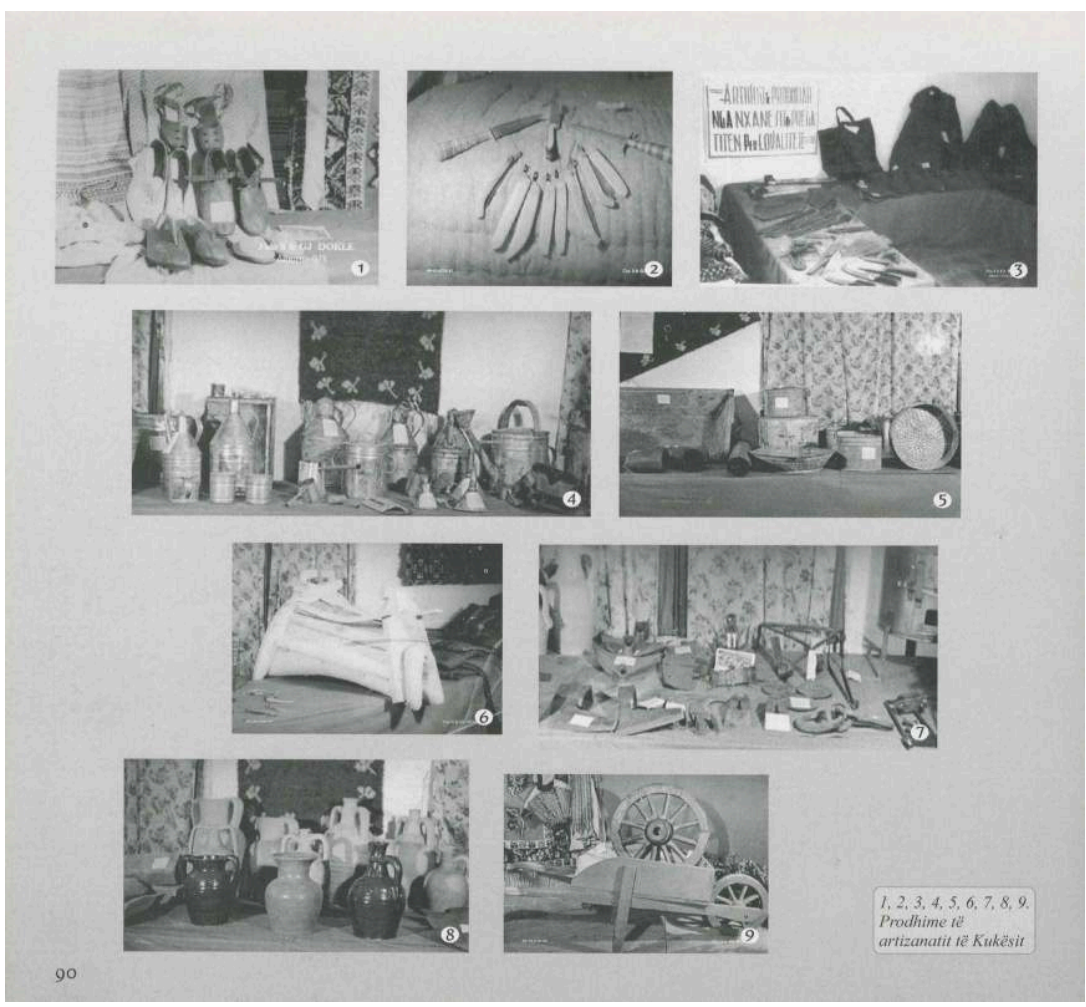

Dokle, 2014, p. 90

Par ailleurs, l'industrialisation, centrale dans la propagande à l'échelle nationale, n'est pas absente de cette région rurale, comme le montrent les images de la mine de cuivre de Gjegjan, la plus importante d'Albanie ${ }^{14}$, et celles de l'inauguration et de l'activité de l'usine de traitement du cuivre de Rexhepaj, dans les années 1962-1964 (p. 84) (fig. 19). Les chapitres suivants, qui traitent de l'éducation, du système de santé et des activités sportives, montrent de même à quel point les photographes avaient pour double tâche de témoigner de la modernisation de la société et de documenter les aspects de l'existence en voie de disparition. 
Fig. 19. Exploitation du cuivre : « 1-3. Inauguration des travaux de construction de l'usine de cuivre, Rexhepaj, 1962 ; 4 . Vue du chantier de l'usine de cuivre, Rexhepaj, $1963 ; 5-8$. Dans la mine de cuivre de Gjegjan, 1964 »

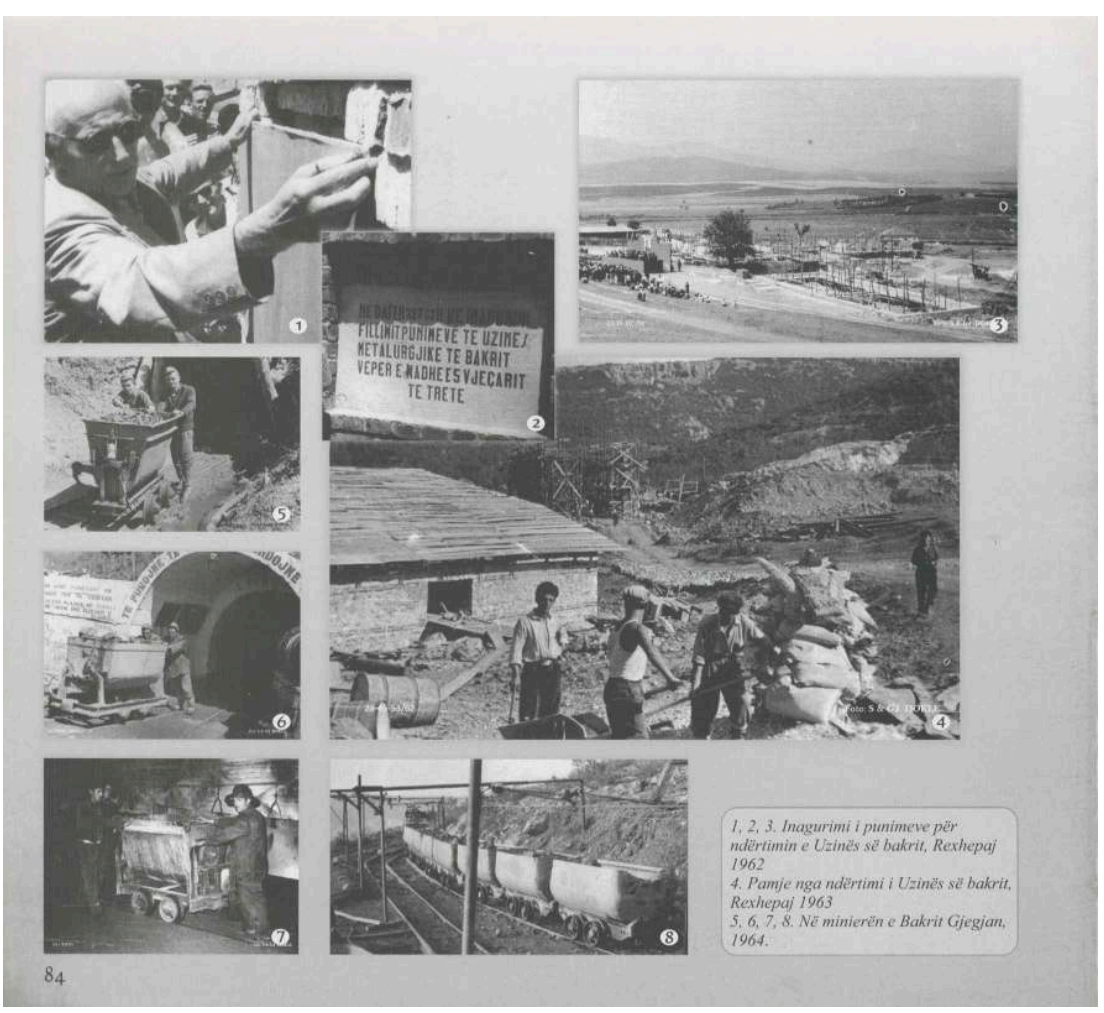

Dokle, 2014, p. 84

Le traitement de la modernisation et du passage du temps est bien présent dans l'album de Petrit Kumi, mais de façon différente. Les pages consacrées au "village socialiste » (p. 54-73) témoignent d'une certaine idéalisation de la vie au village, absente de l'album Dokle, visible dans la mise en valeur des paysages ou dans les gros plans de paysans et de paysannes souriants. Le contraste entre tradition et modernité est volontiers mis en scène sur une même photographie, alors qu'il n'apparaît que dans la juxtaposition des clichés chez les Dokle. Il en va ainsi de la photographie des paysannes de Zagori, chevauchant des ânes sur un fond de panneaux de signalisation routière tandis qu'un pylône de haute tension se dresse à l'arrière-plan (1989, p. 65) (fig. 20); ou encore de celle d'ouvrières de la coopérative agricole de Fan, en costume traditionnel, quittant une vaste parcelle labourée par un tracteur à chenilles (1974, p. 73) (fig. 21). 
Fig. 20. « Jour de travail en Zagori, Gjirokastër, 1989 »

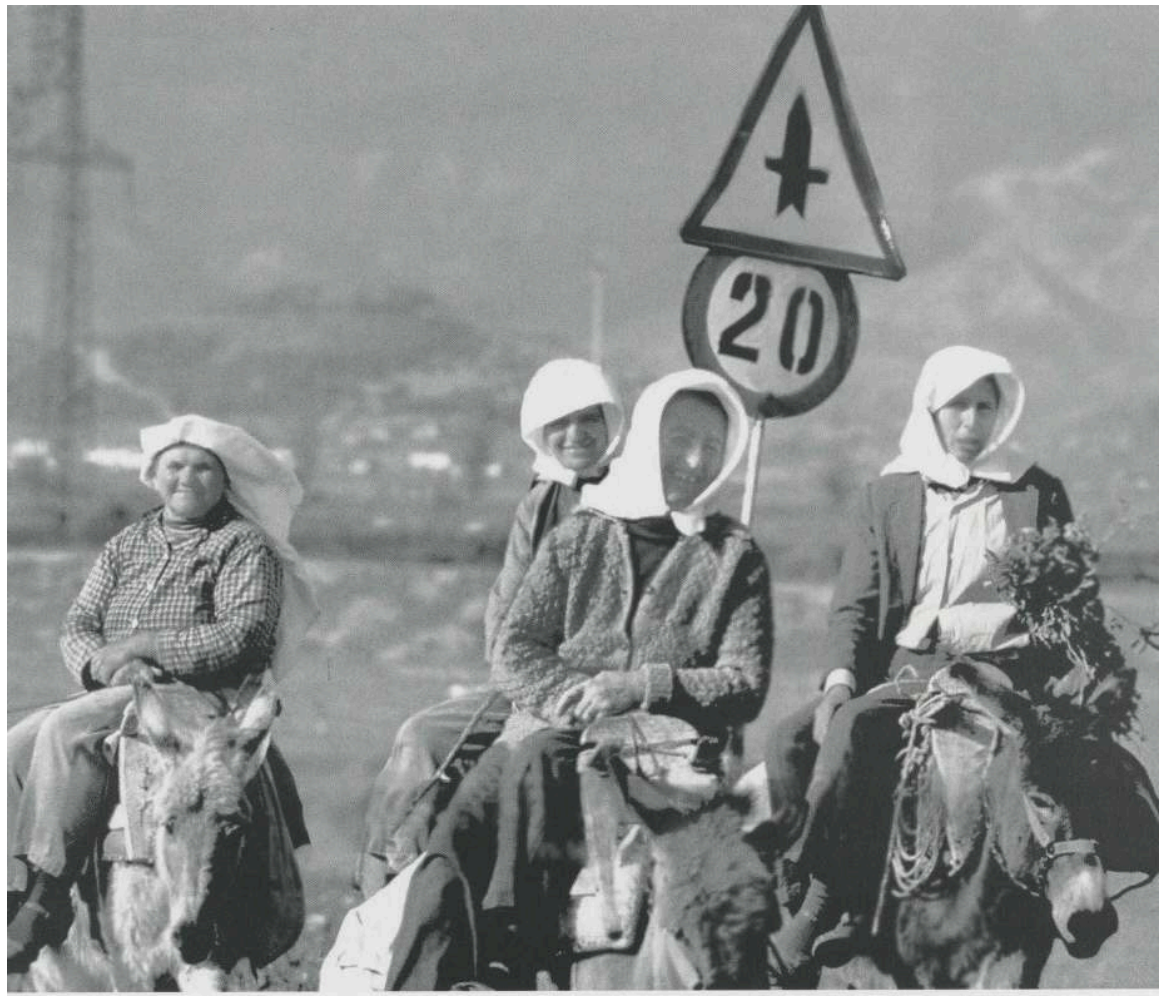

Kumi, 2013, p. 65

Fig. 21. « Ouvrières de la Coopérative agricole de Fan, Mirditë, 1974 »

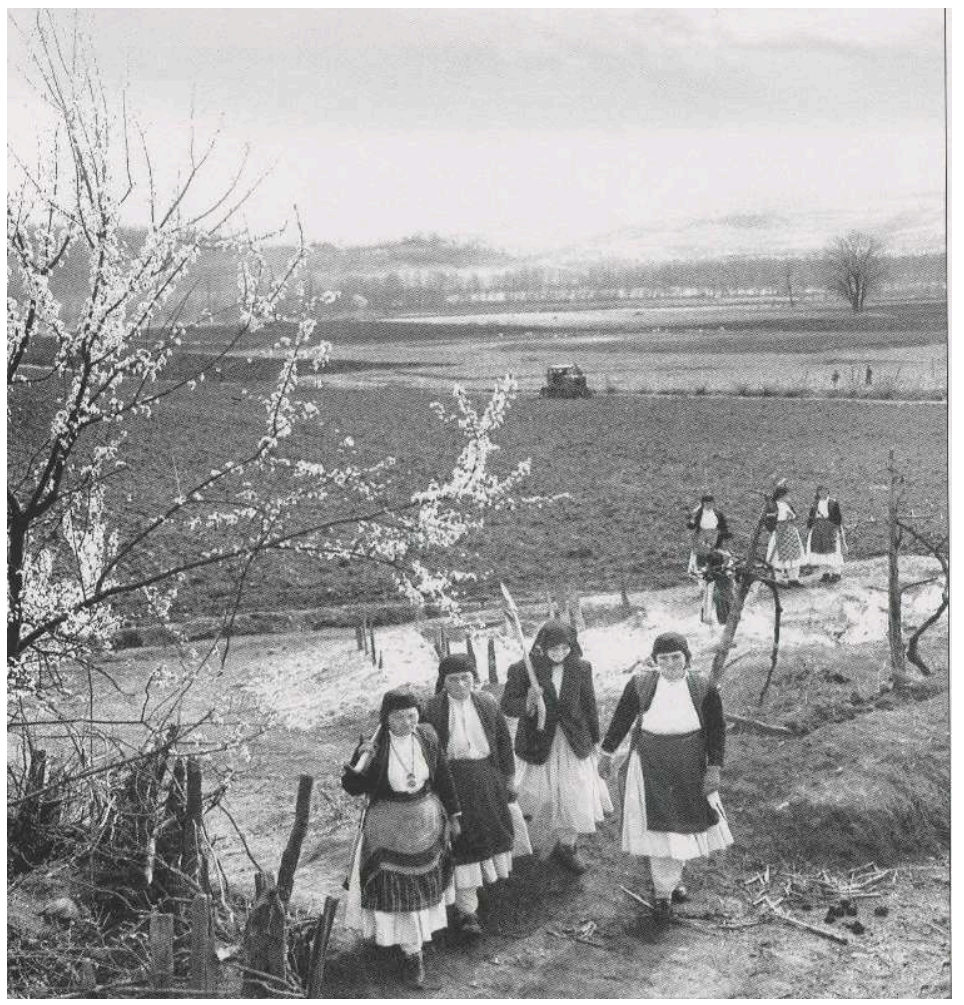

Kumi, 2013, p. 72 
Petrit Kumi a photographié à de nombreuses reprises les usines et les chantiers qui, dans la revue Ylli comme dans le reste de la presse, symbolisaient l'industrialisation et la modernisation de l'Albanie jusque dans les années 1970. Ces photographies sont peu reproduites dans l'album, comme si elles témoignaient d'une soumission trop flagrante à l'idéologie de l'époque. On y voit au contraire quelques portraits d'ouvriers individualisés (certains sont nommés), en accord avec le propos général de l'album qui est de mettre en avant les "gens» et la «vie». Cependant, la modernisation de la société apparaît avant tout dans les nombreux portraits de scientifiques, médecins, sportifs, écrivains ou acteurs réalisés sur leur lieu de travail ou à leur domicile. Il s'agit cette fois de rompre avec l'image d'une société albanaise rurale et arriérée et de montrer combien les élites albanaises sont proches de celles des sociétés "avancées ", pour reprendre une expression de l'époque. Au moment de la prise de vue, ces portraits d'écrivains, de scientifiques ou de sportifs avaient aussi une valeur exemplaire; ils contribuaient à mettre en avant des " héros » dont le modèle devait être suivi, sur le principe de l'«émulation socialiste» mise en œuvre dans les usines, les écoles ou les coopératives agricoles et à laquelle tous les photographes participaient. Aujourd'hui, leur réception est différente. Pour le sculpteur Thoma Thomai, l'un des préfaciers de l'album, ces portraits permettent aux modèles de se retrouver et de "se voir euxmêmes aux beaux moments de leur jeunesse » (p. 10), d'une façon qui laisse penser que cette mise en scène publique des photographies a un effet sur la mémoire individuelle. De fait, les réactions suscitées par ces portraits, notamment de sportifs ou d'acteurs qui furent des célébrités de la période communiste, relèvent de la nostalgie et de l'évocation d'une période révolue qui correspond, pour les survivants d'aujourd'hui, aux années d'enfance ou de jeunesse.

Le deuxième aspect saillant est l'exaltation de l'activisme et du collectif. Dans toutes ces images, les transformations n'apparaissent pas seulement comme un effet du passage du temps : elles sont aussi et surtout le résultat d'une volonté et d'une action politiques. Elles sont de surcroît le résultat d'un effort collectif et d'une adhésion massive à l'entreprise de modernisation. En dehors des quelques portraits d'Enver Hoxha, le pouvoir politique est peu représenté dans l'album de Petrit Kumi. Sa présence est pourtant sensible dans de nombreuses images, par exemple dans les slogans politiques ornant les stades, et elle est soulignée dans les textes qui les accompagnent. Les autorités, principalement locales, sont au contraire largement représentées dans l'album des époux Dokle. Le chapitre sur la chronique politique, en particulier, rassemble de nombreuses images de réunions politiques, d'élections, de défilés et de cérémonies commémoratives présidées par des officiels. Les deux albums, quoique différemment, font une large place aux «actions » qui, par leur nom comme par les représentations visuelles qu'elles suscitent condensent, à elles seules, bien des aspects de cette période historique. La figure de l'« actionniste », en particulier féminine, prend à cet égard un caractère iconique, dans le sens où ses représentations visuelles (en photographie, mais aussi en peinture, en sculpture, en dessin ou encore au cinéma) matérialisent un ensemble discursif mêlant l'exaltation du travail physique, de la jeunesse, du sacrifice de soi et de l'action constructive sur l'environnement (fig. 22) ${ }^{15}$. Il n'est sans doute pas anodin qu'une telle figure occupe une place centrale sur la photographie de couverture de l'album de Petrit Kumi : on y voit une jeune fille, les cheveux serrés dans un foulard portant le sigle de l'Union de la jeunesse du travail 
d'Albanie (BRPSH), organisation qui encadrait les actions, souriant malgré l'effort qu'elle fournit pour pousser un wagonnet chargé de terre.

Fig. 22. « Lida, actionniste du lycée d'Elbasan, sur le chantier ferroviaire Elbasan-Librazhd, 1971 »

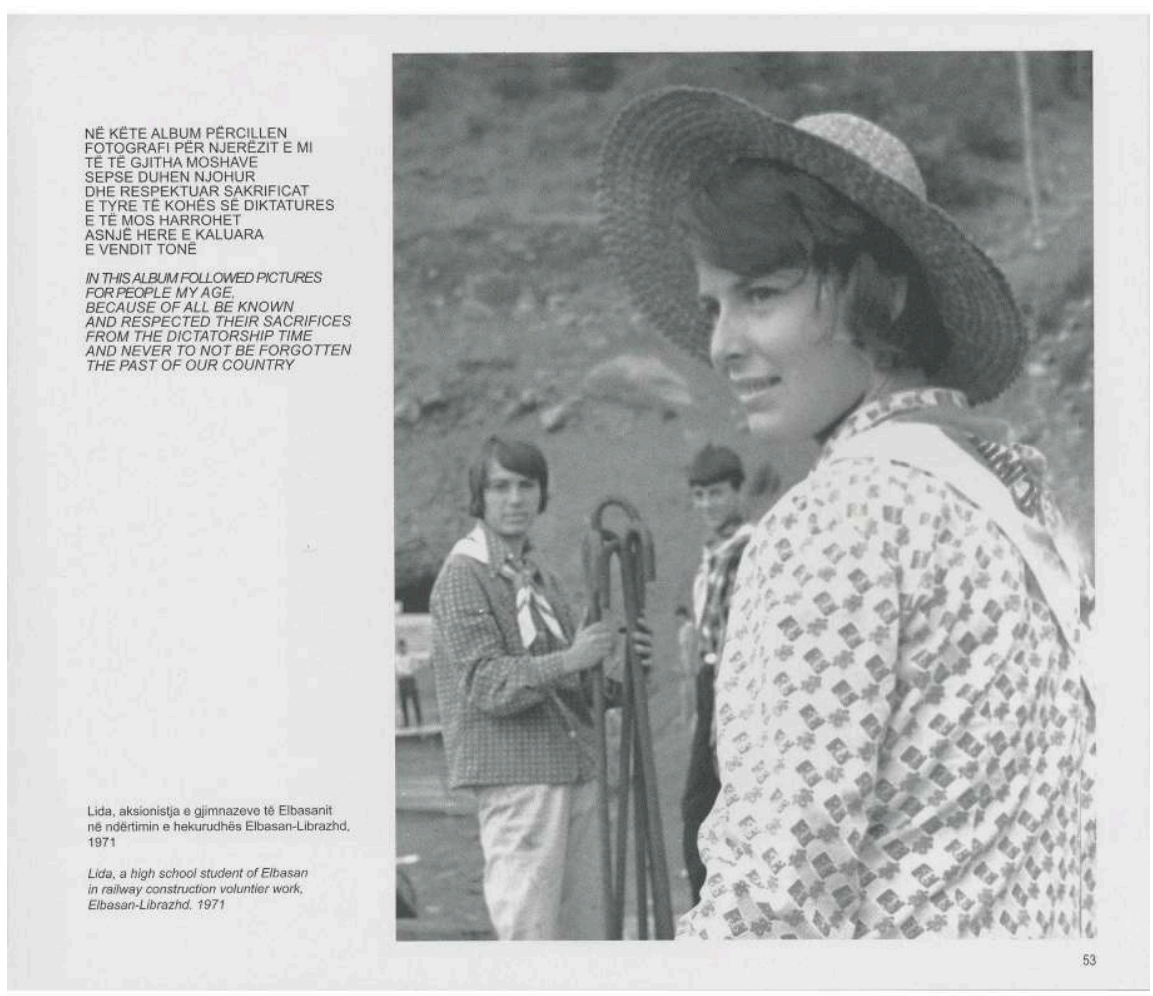

Kumi, 2013, p. 53

La section consacrée au " travail volontaire » (puna vullnetare, p. 42-53) mêle des scènes collectives mettant en avant la participation massive et l'enthousiasme des jeunes gens et des portraits individuels de jeunes filles. La dimension spatiale est particulièrement marquée: les actionnistes remplissent tout le cadre de la photographie (p. 42), se répartissent sur tous les plans (p. 43, 44, 47) (fig. 23) et le résultat de leur travail s'inscrit dans le paysage de façon monumentale (p. 50, 51) (fig. 24). Prises pour la plupart dans les années 1970, ces images ne portent bien sûr aucun message critique sur les "actions". Le texte qui les accompagne, plus curieusement, désamorce toute tentation critique à leur égard en minimisant l'origine idéologique et communiste des actions pour mettre en avant une motivation patriotique : «Les jeunes travaillèrent avec abnégation, mais ce n'était pas l'idéologie communiste qui les motivait et les inspirait ; c'était l'amour de la Patrie. Le temps a montré que c'est précisément cette jeunesse qui apporta dans les années 1990 la démocratie et la liberté tant attendues » (p. 46). Ces images de propagande se trouvent ainsi légitimées et gagnent un caractère intemporel. 
Fig. 23. "Travail volontaire»

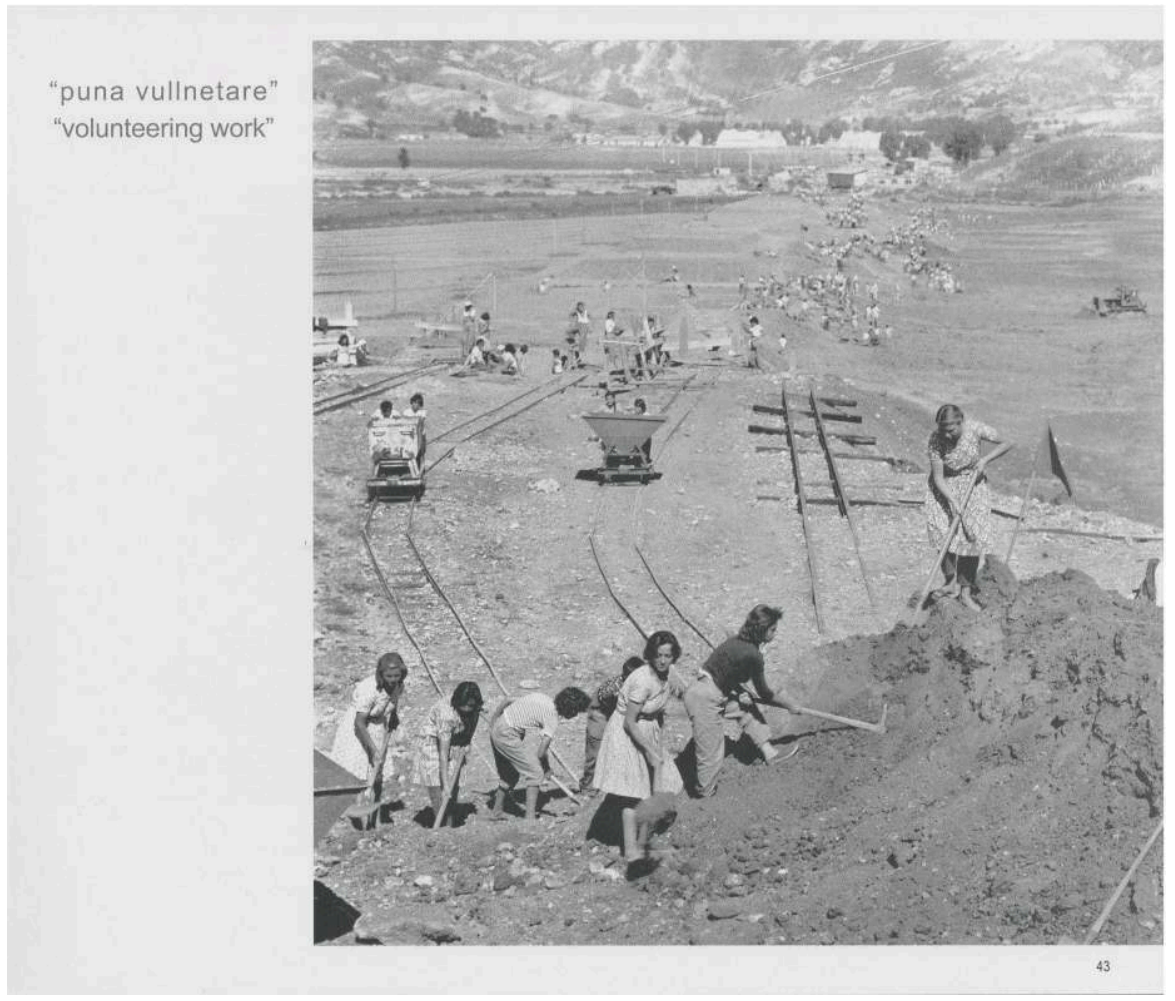

Kumi, 2013, p. 43

Fig. 24. « Le travail 'volontaire' de la jeunesse pour la construction de la voie ferrée RrogozhineLushnjë »

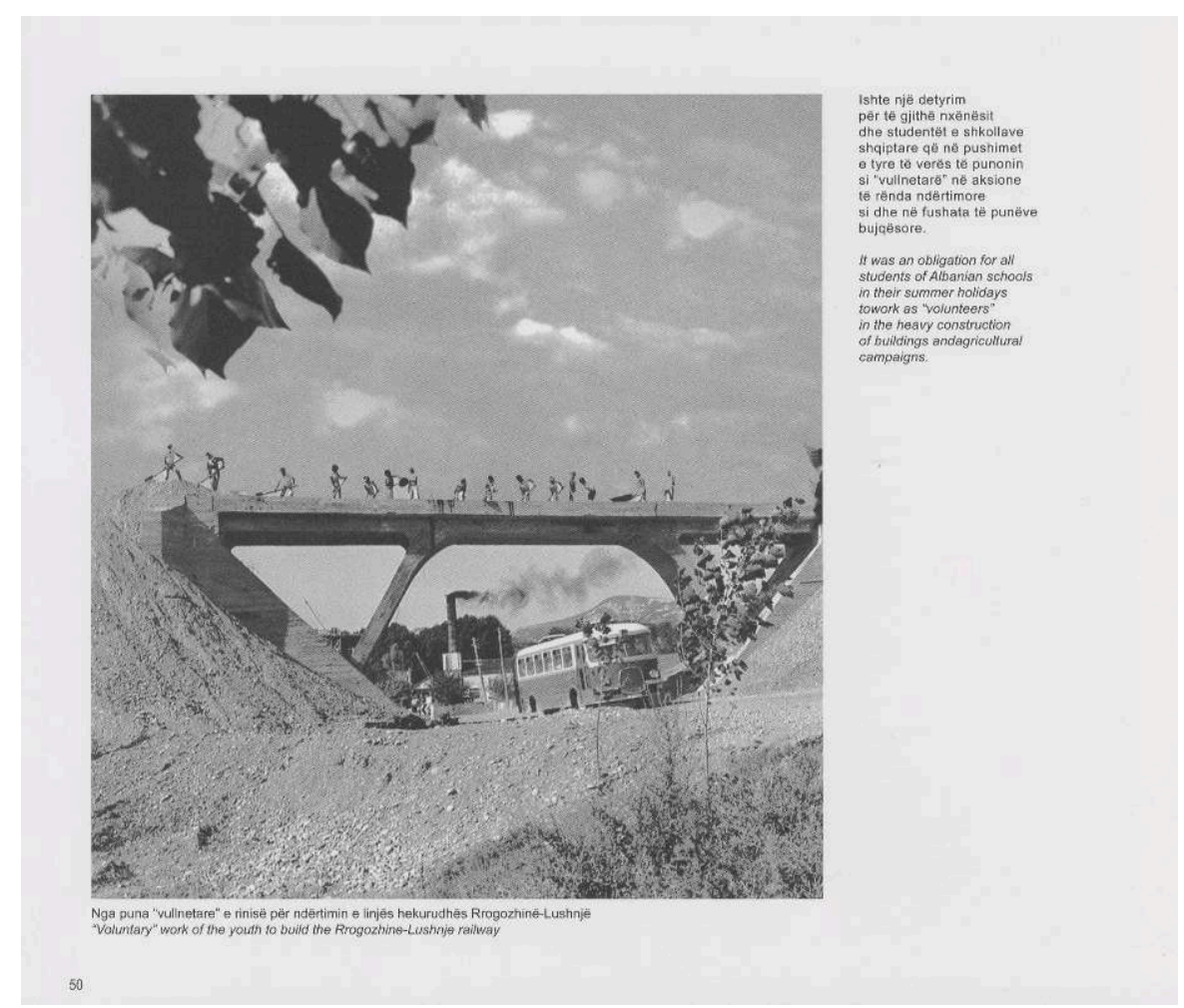

Kumi, 2013, p. 50 
Le sujet est, là aussi, traité différemment dans l'album des époux Dokle. Les actions apparaissent principalement dans le chapitre sur la vie politique, ce qui témoigne, s'il en était besoin, de leur dimension idéologique. De plus, certaines images de la vie économique ont vraisemblablement été prises en de telles occasions et le chapitre sur l'éducation comporte aussi une scène de "retour d'action des lycéens ", datée de 1966 (p. 136) (fig. 25). Les photographies d'actions ne sont pourtant pas rassemblées dans une section particulière, mais réparties au milieu de représentations d'autres activités collectives : célébration du $1^{\mathrm{er}}$ mai, anniversaire de Staline, conférences du comité local $\mathrm{du}$ parti, inaugurations, élections. Elles partagent d'ailleurs avec ces dernières un caractère massif et frontal : à quelques exceptions près, représentant des actionnistes au travail (p. 31, 54,57), il s'agit de larges groupes pris en plongée et à distance suffisante pour entrer dans le cadre. On apprend que la population de Kukës participa à des actions dès l'année 1945 (p. 24), puis en 1952-1953 pour le creusement d'un canal (p. 30-33) (fig. 26). Les autres actions datent des années 1960, moment qui vit effectivement, suite à la fin de l'assistance économique de l'URSS, le recours massif au «travail volontaire». On trouve par exemple une photographie intitulée «Le départ des actionnistes pour la construction du chemin de fer Rrogozhinë-Fier », datée de 1967 (p.60) (fig. 27). Une troupe de femmes et de jeunes filles, certaines en costume traditionnel, est rangée sur une place de la ville dans l'attente du départ. Il est intéressant de comparer cette image avec celle prise par Petrit Kumi sur le chantier de cette même action (p. 50) (fig. 24, ci-dessus): le traitement en est beaucoup plus "moderne", le plan incluant un pont en béton sous lequel passe un autocar tandis qu'une cheminée d'usine fume à l'arrière-plan.

Fig. 25. « Retour d'action des lycéens, Kukës 1966 »

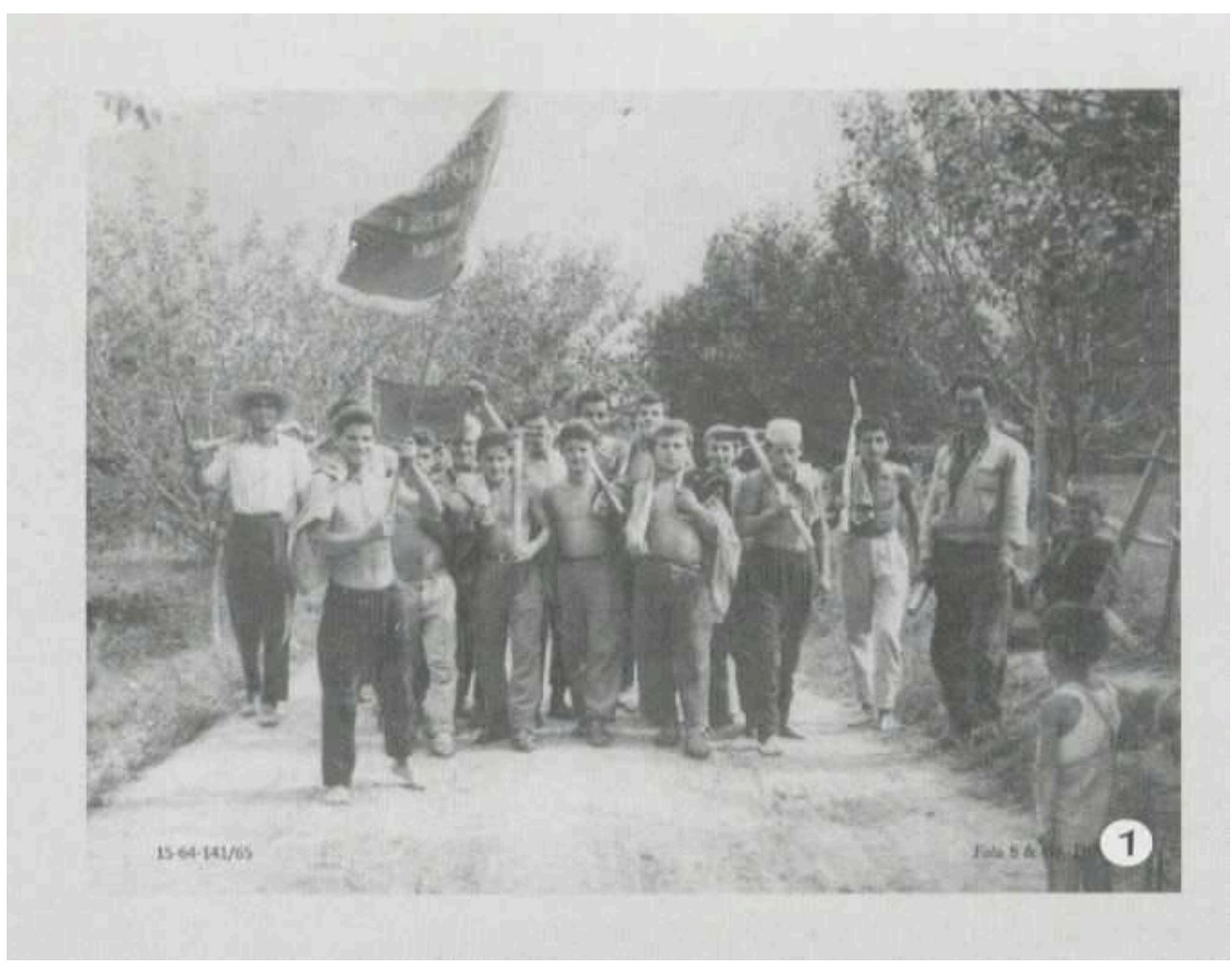

Dokle, 2014, p. 136 
Fig. 26. « Retour des actionistes de la centrale hydroélectrique de Ulzë, Kukës 1953 »

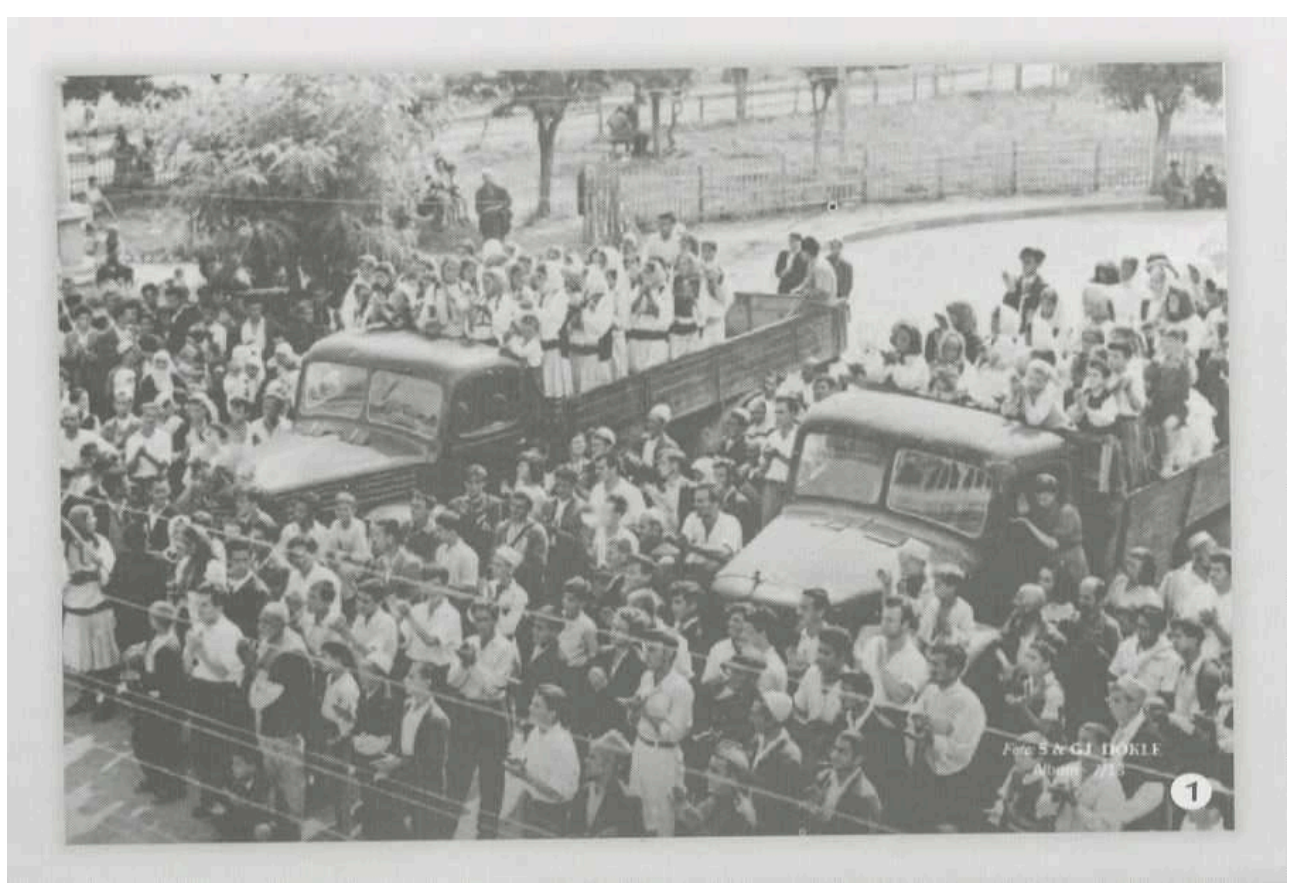

Dokle, 2014, p. 33

Fig. 27. « Départ des actionistes pour la construction du chemin de fer Rogozhinë-Fier, Kukës $1967 »$

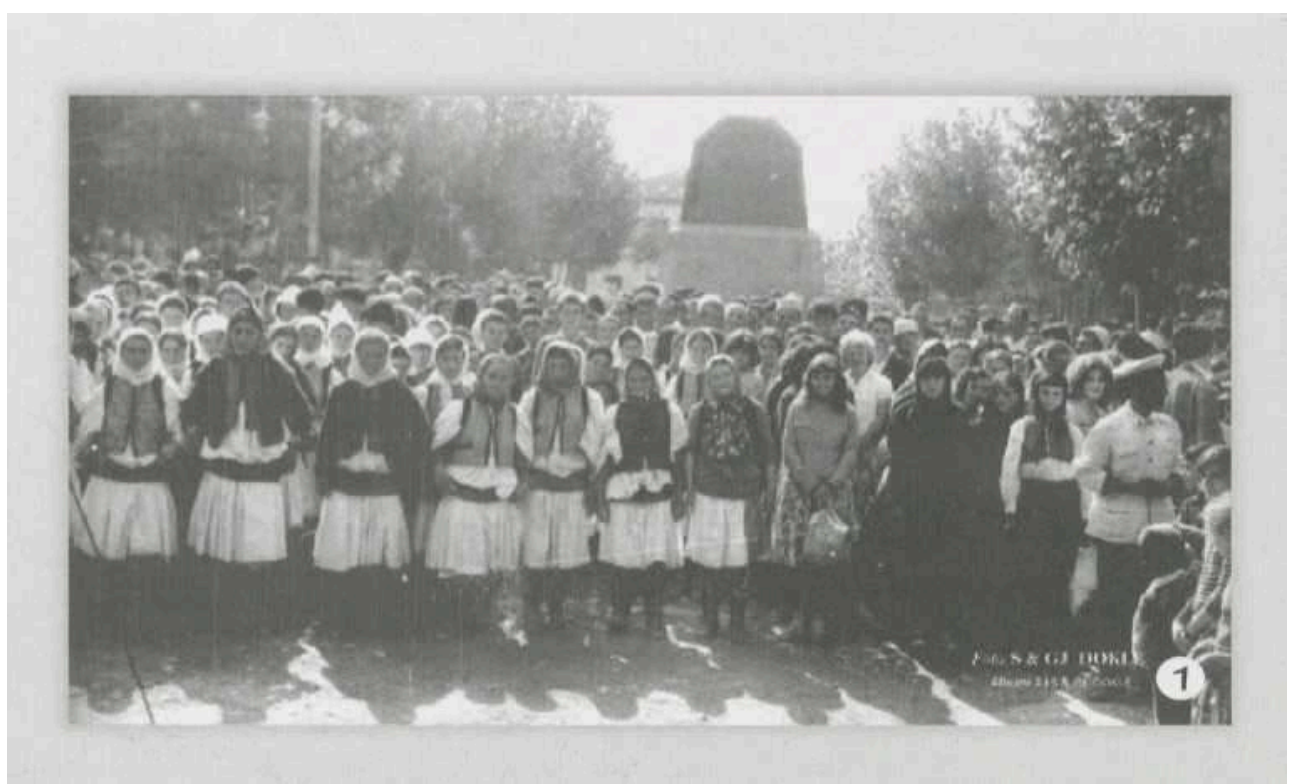

Dokle, 2014, p. 60

Le texte introduisant le chapitre de l'album Dokle sur la vie politique est beaucoup plus critique que chez Petrit Kumi: les actions y sont mises sur le même plan que les élections, manifestations, défilés, meetings, inaugurations, hommages, cérémonies mortuaires, conférences, réunions, rassemblements, visites d'Enver Hoxha et préparation militaire de la population, comme autant de mises en scènes " grotesques » 
visant à masquer « la tragédie de la défaite de l'individu et son avalement par la foule » (tragjedinë e çbërjes së individit e gëllititjes së tij nga turma, p. 20). L'impression formée par cette succession d'images de foules défilant devant les tribunes officielles ou applaudissant les détenteurs de l'autorité politique est, de fait, celle de la monotonie et de la pauvreté de l'imagination visuelle. Toutes les occasions, de la célébration du $1^{\mathrm{er}}$ mai à l'inauguration d'une cabine électrique, donnent lieu aux mêmes images de foules passives face à la théâtralité du pouvoir. Si ces images constituent une mémoire de la période communiste, elles le font d'une manière extrêmement normée et contraignante. Cela nous permet d'introduire un dernier point.

\section{La valeur des images}

30 En troisième lieu, en effet, les deux albums posent la question de la valeur de l'image dans ce type de régime politique. Les moyens accordés aux photographes et l'ampleur des dispositifs mis en place pour produire et contrôler la photographie (et plus tard la télévision) ne sont certainement pas spécifiques au contexte albanais. Les pratiques des communistes albanais sont à cet égard largement influencées par les pratiques soviétiques et, dans une moindre mesure, chinoises. On peut rappeler ici que Petrit Kumi a travaillé, dans la deuxième moitié des années 1950, comme graphiste de la revue Miqësia ( L'Amitié »), vitrine des relations albano-soviétiques avant la rupture de 1961 ; et qu'il a effectué un séjour de plusieurs mois en Chine dans les années 1960, séjour qui, de son propre aveu, lui a appris des techniques de "retouche et de manipulation de la photographie politique » (p. 246).

31 En évoquant la quantité et la diversité des images produites, ainsi que les forces mobilisées pour l'organisation de cette production, ces albums rappellent donc le caractère fondamental de la fabrique des images pour le pouvoir communiste et, audelà, pour les régimes dits "totalitaires». La production et la publication d'albums photographiques représentaient déjà un enjeu important à l'époque communiste, de même que les expositions. Sans entrer dans les détails d'une histoire des albums photographiques albanais, qui reste à écrire, on peut signaler à titre d'exemple que les grandes dates anniversaires étaient l'occasion de publier des albums montrant le chemin parcouru et les résultats obtenus. Les premiers albums imprimés en couleurs étaient une source de fierté et leur destination était aussi le public étranger. La pratique semble avoir culminé à la fin des années 1970 et après la mort d'Enver Hoxha (1985), lorsque plusieurs albums luxueux, déclinés en plusieurs langues, furent publiés en hommage au dictateur. Petrit Kumi a eu l'occasion de contribuer à au moins l'un d'entre eux ${ }^{16}$. Enfin, on ne peut manquer de penser à l'album de photographies historiques publié en 1982 (pour le $70^{\mathrm{e}}$ anniversaire de l'indépendance nationale) à partir du fonds de la photothèque Marubi de Shkodër ${ }^{17}$. Pour la première et la dernière fois pendant la période communiste, la photographie était sollicitée seule (les textes se réduisant à de courtes légendes) pour raconter l'histoire nationale et proposer une mémoire en images d'un temps révolu. Comme on le sait aujourd'hui, de nombreuses photographies avaient pour l'occasion été recadrées ou retouchées.

Les deux albums qui nous concernent ne se contentent donc pas de remettre en circulation des images de l'époque communiste; ils prolongent aussi une pratique de mise en image du passé et de cette période historique en particulier. Cela est nettement visible, comme nous l'avons signalé, dans le plan adopté par l'auteur de l'album Dokle, 
qui reprend les grandes rubriques sous lesquelles se déclinait à l'époque la réalité sociale : géographie, histoire, économie, éducation, sport, culture, santé, traditions et art. Les images publiées aujourd'hui acquièrent ainsi un caractère ambigu : produites en fonction d'une idéologie et au service d'un récit bien précis, mais désormais caducs, elles sont susceptibles de prendre de nouvelles significations extérieures ou opposées à eux. Les innombrables scènes de commémoration ou d'inauguration reproduites dans l'album Dokle semblent aujourd'hui dérisoires ou grotesques : célébration du Traité de Varsovie à Kukës en 1956 (p. 35); inauguration de la cabine électrique du village de Domaj en 1969 (p. 64) (fig. 28); défilé de tracteurs et de charrettes pour le $1^{\mathrm{er}}$ mai 1969 à Kukës (p. 66). Quant aux images de l'«homme nouveau» (njeriu i ri) ou du "peuple soldat " (populli ushtar), centrales dans la propagande de l'époque, elles ne font l'objet que d'une double-page chacune dans l'album de Petrit Kumi (p. 146-147 et 152-153) et dans une rhétorique visuelle qui leur ôte tout caractère héroïque pour en faire des exercices obligés ou des curiosités d'un autre temps (fig. 29 et 30).

Fig. 28. «Inauguration de la cabine électrique, Domaj 1968 »

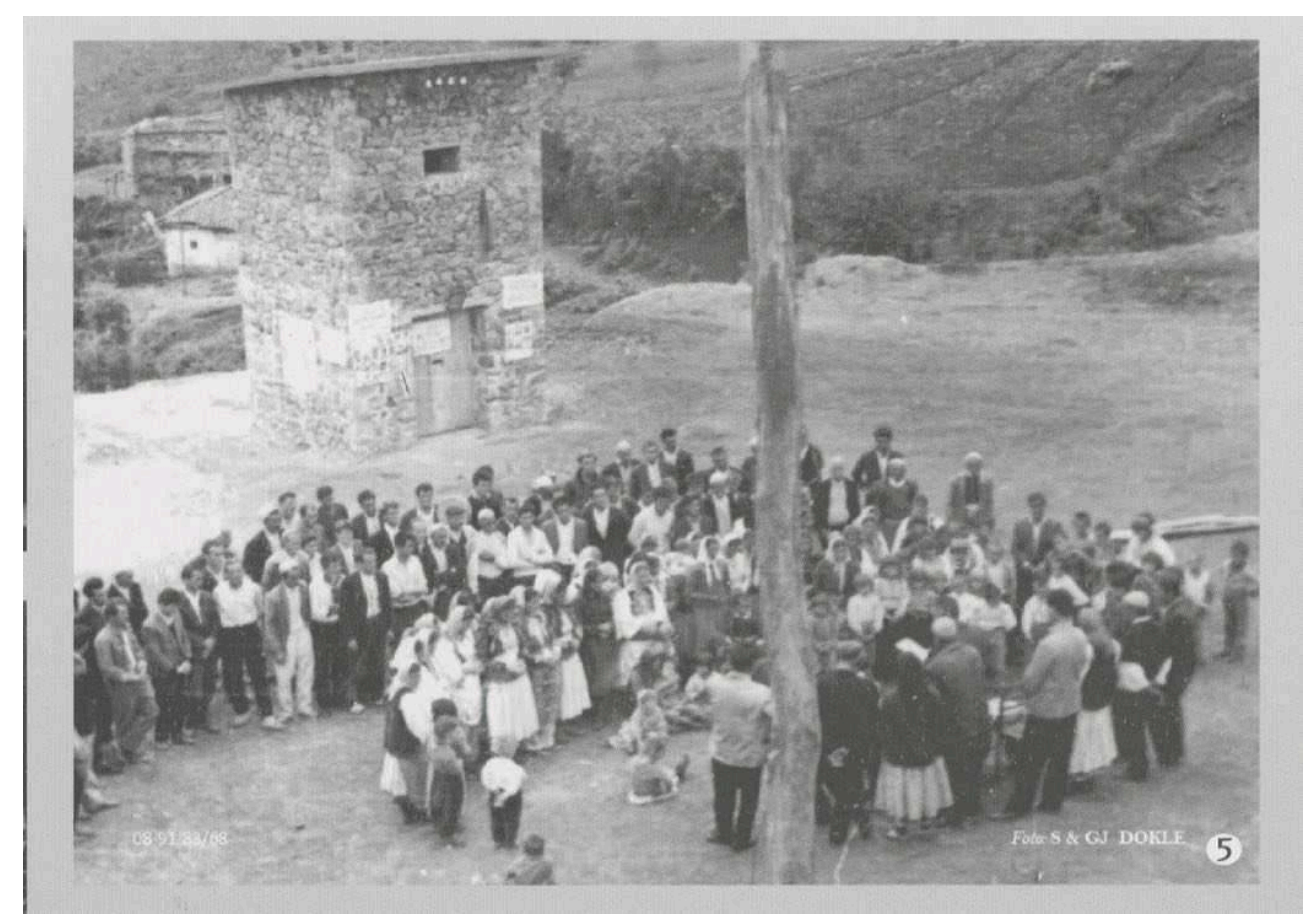

Dokle, 2014, p. 64 
Fig. 29. « L'homme nouveau »

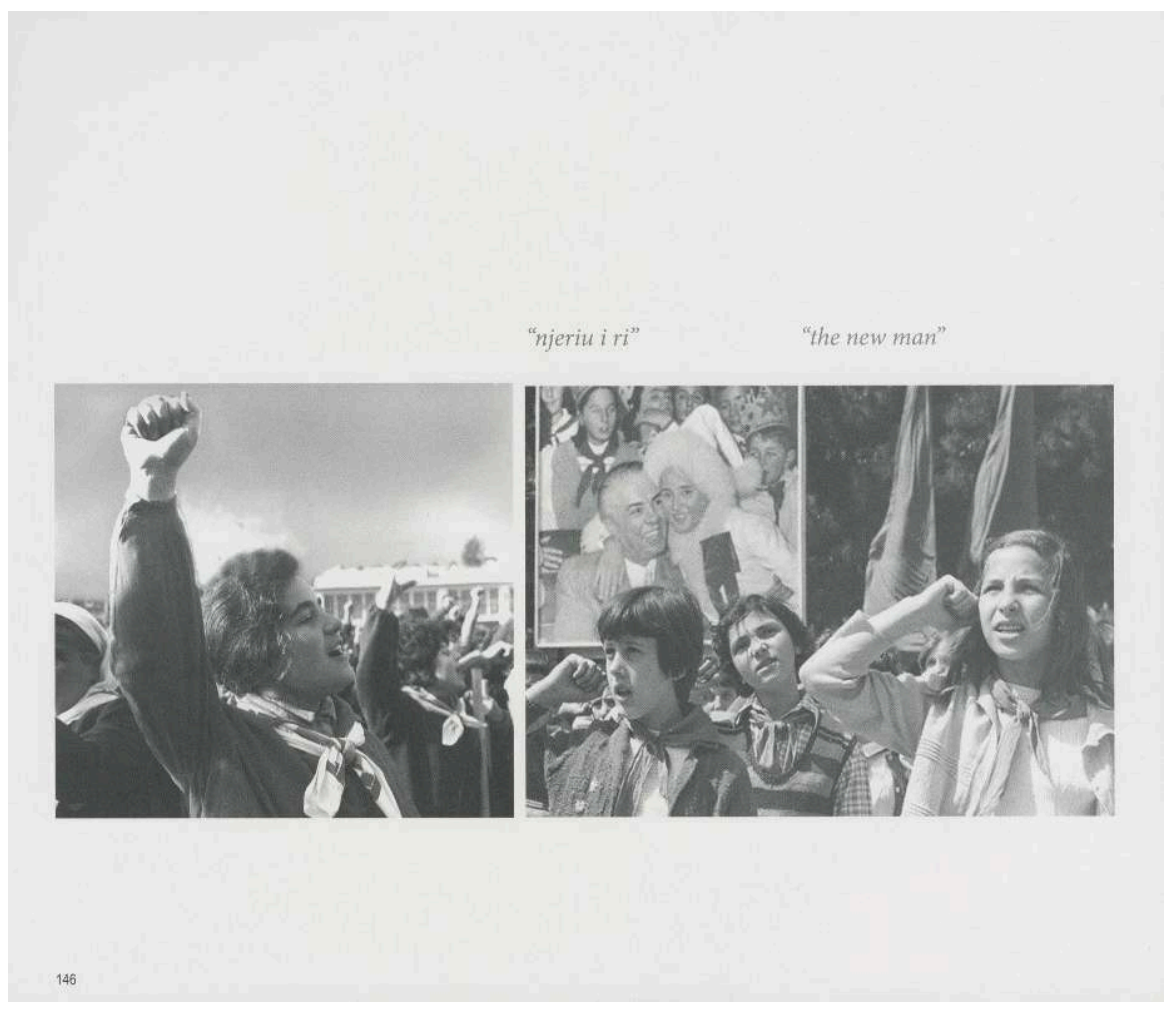

Kumi, 2013, p. 146

Fig. 30. « Le peuple soldat »

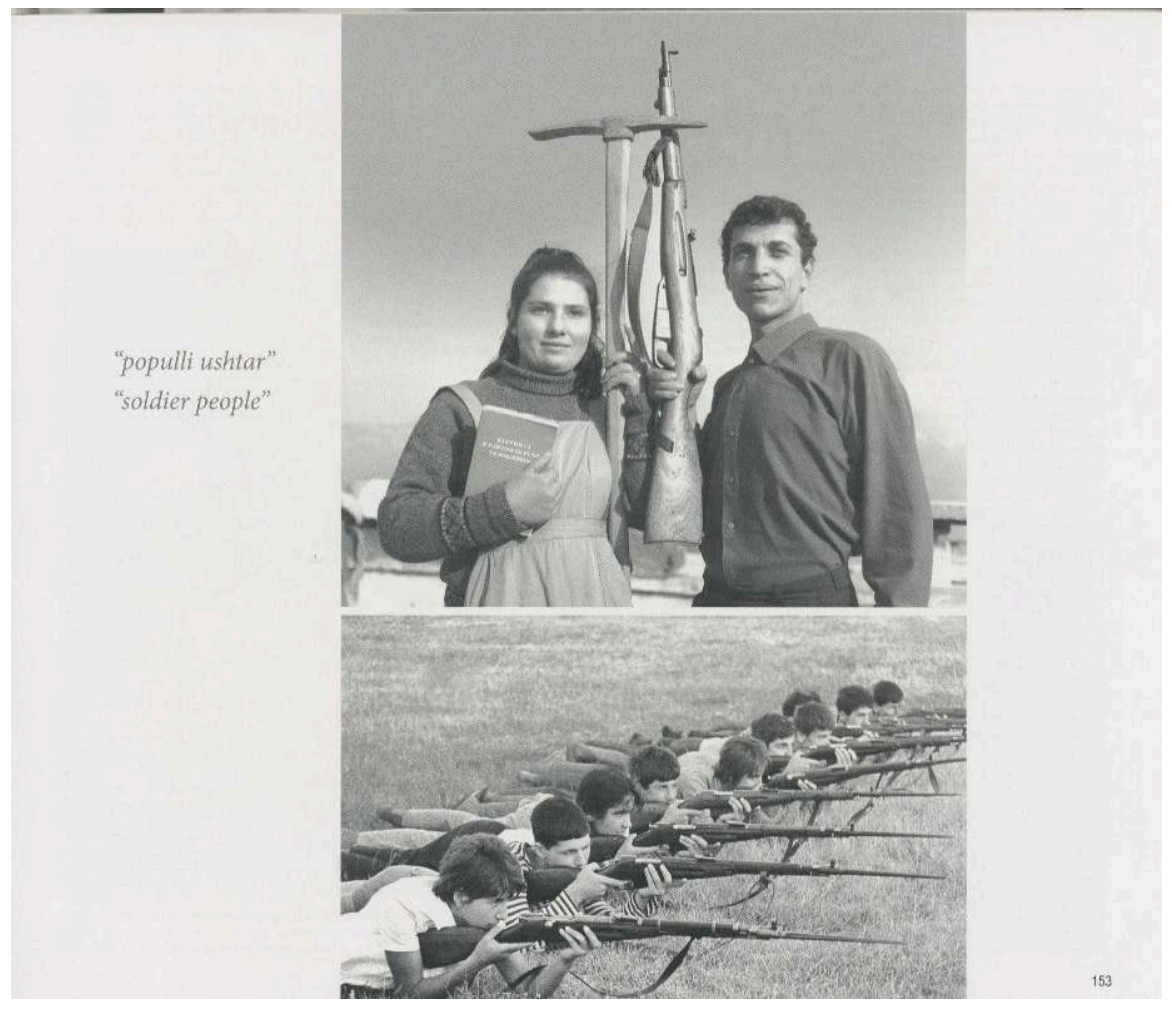

Kumi, 2013, p. 153 
Un point en particulier mérite d'être souligné : toutes ces images font sentir combien, contrairement à la conception courante à l'époque et toujours transmise par les textes des deux albums, la photographie n'est pas le miroir de la réalité, mais contribue au contraire à faire advenir la réalité. On peut à cet égard s'interroger sur la spécificité du rapport à l'image des régimes révolutionnaires, c'est-à-dire engagés dans la fabrication d'une nouvelle société, et sur l'importance que prend l'action de donner à voir, par la photographie ou d'autres moyens visuels, le changement et l'irruption d'une nouvelle réalité. Cela est vrai de toutes les images qui rendent compte des transformations du pays et de la "construction du socialisme» comme de celles qui témoignent de l'enthousiasme populaire et de l'adhésion des masses au pouvoir des communistes. Cela est vrai aussi des nombreuses images de cérémonies et de monuments commémoratifs qui rappellent comment la photographie fournissait un cadre au souvenir et à quel point la légitimité du pouvoir reposait sur la fabrication et la manipulation de la mémoire et de l'histoire, comme l'a bien montré Tzvetan Todorov ${ }^{18}$. Ces albums rappellent donc que tout n'était pas photographiable et que ce qui l'était devait être photographié conformément à la doctrine du «réalisme socialiste » qui prévalut en Albanie, en photographie comme dans tous les autres arts, jusqu'à la fin de la dictature. Par leur apparente mise en scène, par la répétition du " sourire socialiste ${ }^{19}$ » comme par l'utilisation de symboles dont le sens était largement partagé, ces photographies relèvent de l'artifice et ne peuvent être vues seulement comme le reflet d'une réalité historique, mais comme des éléments fondamentaux de cette réalité. La conception commune aujourd'hui de la photographie de la période communiste est bien celle d'un artifice au service de l'idéologie et du pouvoir politique et c'est pour cela qu'elle est dévalorisée par rapport à celle de la période précédente. "Ceux qui étaient photographiés ", écrit un des rares historiens de la photographie albanaise à propos de cette période, «simulaient et posaient devant l'appareil, devenant, pour ainsi dire, des acteurs de théâtre ${ }^{20}$.»

Le fait que les photographies publiées dans les deux albums risquent d'être perçues uniquement sous cet angle artificialiste est sensible dans l'insistance avec laquelle les auteurs tentent de leur donner une valeur de vérité ancrée dans la « réalité » et dans la transparence. Dans l'album Dokle, nous l'avons vu, l'auteur insiste sur le caractère spéculaire de l'image photographique qui reflète comme un miroir la "vie » (jetë) politique, économique, éducative, sportive, artistique et culturelle. La photographie est un moyen de "chercher" (kërkoj), "déceler» (hetoj) et "découvrir» (zbuloj) les multiples aspects " offerts par la réalité » (që të falë realiteti) (p. 204). Les époux Dokle se distinguent à cet égard par leur capacité à saisir, par la photographie, "toute la dimension temporelle et spatiale" (të gjithë dimensionin e tyre kohor dhe hapsinor) des scènes qu'ils sélectionnent (p. 4). Leurs photographies sont donc des «témoignages authentiques » (dëshmi autentike) (p.178) dont la lecture est toujours «claire » (qartë) (p. 20, 102, 138, 170, 178). Le vocabulaire utilisé dans l'album Kumi est similaire dans son insistance sur la «nature » (natyrë), la « réalité » (p.11) et surtout sur la «vie » comme unique objet du photographe et sur la capacité de ce dernier à la saisir « dans tous ses aspects » (në të gjitha aspektet a saj) (p. 4) et de manière réaliste (p. 9, 10, 248) ou authentique (p.11). Cela est rendu possible par la capacité du photographe à montrer ce qu'il y a "sous les apparences" (më thellë se sa dukej) (p.10) et à "rechercher la lumière précisément là où les autres ont du mal à la voir ou refusent de la regarder " (ka kërkuar dritën pikërisht atje ku të tjerët e kanë vështirë ta shohin, apo nuk kanë dashur ta 
shikojnë) (p. 11). Les deux albums contribuent donc à la fois à raviver et à conjurer le souvenir d'une époque où la photographie était suspecte et manipulable.

\section{Ce que ces albums font au présent}

Ces albums nous disent, enfin, quelque chose sur le présent et sur la façon dont la mémoire de la période communiste constitue un enjeu actuel. Il faut d'abord noter à quel point ils contrastent à la fois avec l'invisibilité dominante de la photographie de la période communiste comme avec ses usages les plus courants. Ces derniers consistent avant tout en la publication, dans la presse écrite, à la télévision ou sur Internet, de photographies accompagnant des "révélations " tirées des archives des institutions communistes et dénonçant les crimes de la dictature. Généralement recadrées et non créditées, elles ne servent que d'illustrations et semblent être choisies en fonction de leur caractère iconique. Quant à l'invisibilité, c'est celle de l'immense majorité de ces images conservées dans des archives publiques ou privées très peu exploitées. Les albums en question rompent avec ces usages en faisant des photographies des objets mémoriels et, plus encore, le support d'une métamémoire. On peut à cet égard avancer qu'ils ont des effets de trois sortes.

\section{La reconnaissance du photographe en auteur}

Premièrement, ils sortent les photographies de l'anonymat et de la catégorie générale de "photographie du communisme" pour leur attribuer des auteurs clairement identifiés. Cela est évident dès la couverture : l'album Dokle porte pour titre "Les photographes Safet et Gjylzade Dokle» tandis que, sur l'album Kumi, le nom du photographe apparaît dans une police de caractères près de trois fois plus haute que celle utilisée pour le titre, souligné de ses propres titres: "Photoreporter, grand maître, artiste méritant». Dans les deux cas, cette revendication d'«autorité" s'accompagne de la reconnaissance d'un regard personnel, exprimée notamment par le recours à la catégorie de photographie artistique. Cela est très net dans l'album de Petrit Kumi, à la fois dans la mise en page, qui s'inspire de celle de livres d'art, et dans les textes du photographe lui-même et de ses préfaciers.

La revendication de regard personnel et artistique se fait différemment dans l'album Dokle, où un chapitre conclusif, bénéficiant d'une mise en page plus aérée, rassemble la production «artistique» des photographes. Cependant, l'auteur prend bien soin de justifier son entreprise par la nécessité d'affirmer la propriété de ces images : « une grande part des photographies des deux époux a été publiée et diffusée sans nom d'auteur. Cela mettait leur contribution sur le même plan que les autres et ne permettait pas de reconnaître l'ampleur et la valeur particulière de ce qu'ils nous ont laissé »(p.4). Il prend soin aussi de montrer en quoi la contribution des deux photographes diffère de celle des autres photographes du service public: ils ne se contentaient pas de répondre aux demandes des clients, mais faisaient de nombreuses photographies de leur propre initiative, ce qui supposait une plus grande ouverture d'esprit et un plus grand talent photographique ; leur travail ne s'achevait pas une fois la photographie imprimée et remise au client : tous leurs négatifs étaient indexés et archivés et constituent de ce fait aujourd'hui un "héritage " (trashëgimi), une "chronique photographique de quarante ans d'histoire de Kukës"; ils se sont 
intéressés à l'ethnographie et ont laissé des « témoignages » (dëshmi) qui les distinguent des autres photographes; ils se sont essayés avec succès à la photographie artistique ; et, enfin, ils ont reproduit des «documents rares relatifs à l'histoire de Kukës, les sauvant ainsi de la disparition » (p. 3-4).

Le ton est similaire dans la préface de Thoma Thomai, qui insiste sur le fait que « Petrit Kumi photographiait beaucoup, bien plus que ce qui lui était demandé par la rédaction pour laquelle il travaillait» (p. 10). Dans les deux cas, la publication de photographies de la période communiste revient à affirmer, dans le présent, la valeur de ces images et de leurs auteurs. Elle est une injonction à ne pas oublier leur contribution, qui ne se limite pas à être les photographes du pouvoir communiste, mais justifie leur place dans l'histoire de la photographie albanaise.

\section{Sortie du communisme?}

Deuxièmement, ces albums ont pour effet de banaliser la photographie de cette époque en tant que "photographie de propagande » et "photographie communiste", avec les connotations négatives de ces termes. Sorties de leur contexte d'origine, ces images perdent de leur « pouvoir » d'influencer les sentiments, les comportements et les actes de leurs destinataires de la manière voulue par les autorités politiques de l'époque. Cet effet est atteint dans l'album Dokle par l'accumulation, à l'échelle de l'album comme sur chacune des pages, de reproductions en petit format de photographies qui, d'une certaine manière, se ressemblent toutes. L'insistance sur la valeur documentaire des images contribue aussi à faire oublier leur statut d'instrument de la propagande. L'introduction du chapitre sur le système éducatif est révélatrice de ce glissement de la photographie politique vers le document. Le dernier paragraphe précise que la " mémoire photographique » constituée par les époux Dokle permet de voir clairement "l'arrière-plan du processus d'endoctrinement des enfants"(p.102) à travers la politisation du décor des salles de classes, la participation des élèves aux activités politiques de la ville ou de la région, ou encore la dépendance des institutions scolaires à l'égard des organisations politiques émanant du parti unique. Ce constat, auquel on ne peut que souscrire, passe cependant sous silence la contribution de ces mêmes photographies au processus d'endoctrinement qui n'est donc pas qu'un " arrière-plan " mais la condition même de ces photographies. Les photographies de promotions, les portraits des meilleurs élèves, les images d'activités sportives ou culturelles et celles d'inaugurations de nouvelles écoles faisaient partie de la propagande et contribuaient à former l'image d'un système scolaire efficace et conforme aux exigences de la construction du socialisme. La distanciation se fait aussi par la valorisation des qualités esthétiques des photographies qui, contrairement à l'idéologie qui a présidé à leur production, sont perçues comme intemporelles. La mise en scène des photographies de Petrit Kumi répondrait ainsi avant tout, selon l'un des préfaciers, à des préoccupations artistiques (p.10). Le contexte politique d'origine s'efface donc devant la beauté de l'image et devant l'émotion esthétique qu'elle peut faire naître chez le spectateur d'aujourd'hui.

Un troisième procédé est de mettre en avant la dimension « humaine » (njerëzor) de la photographie face à la violence politique. Cet effet est atteint dans l'album Dokle par le chapitre sur la photographie artistique, qui multiplie les portraits dans lesquels semble transparaître une émotion sincère et les scènes d'enfants évoquant plus facilement que 
d'autres l'innocence et la joie. Le texte introduisant le chapitre sur la vie politique, on l'a vu, insiste de même sur le combat entre l'individu et la dictature (p. 20). La dimension humaine, ou humaniste, de la photographie est nettement plus prononcée dans l'album de Petrit Kumi. Le nombre de portraits individuels et de scènes de la vie quotidienne y est marquant. Même fabriquées, des images comme celle des enseignants aidant leurs élèves à franchir une rivière à gué (p. 23) (fig. 31) ou celle des instituteurs de village (p.57) (fig. 32) sont touchantes par leur simplicité et l'image du bonheur qu'elles transmettent. Dans sa préface, Kadri Gjata prétend, de plus, que dans sa pratique du portrait, Petrit Kumi parvient, derrière le sourire obligé, à saisir l'« état d'esprit » (preokupim shpirtëror) des modèles, la satisfaction, l'amour, la désillusion, la fatigue ou l'agitation, c'est-à-dire leur «humanité » (njerëzore). Le photographe est ainsi, conclut-il, « l'allié intime de l'homme, pas de la politique » (aleat i ngushtë i njeriut, jo i politikës) (p. 11).

Fig. 31. « Les enseignants aident les élèves à traverser la rivière, Librazhd, 1969 »

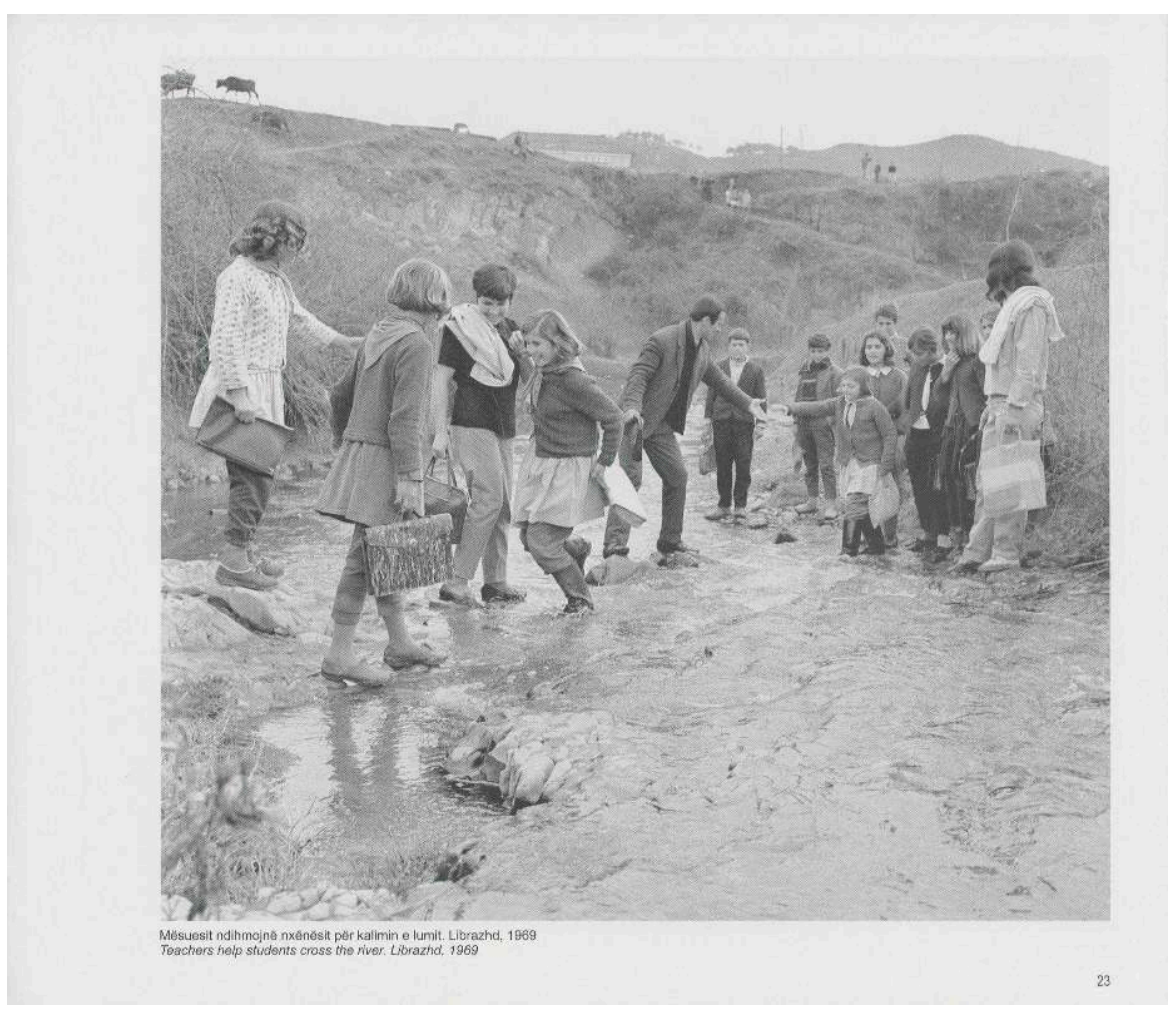

Kumi, 2013, p. 23 
Fig. 32. « Les enseignants du village »

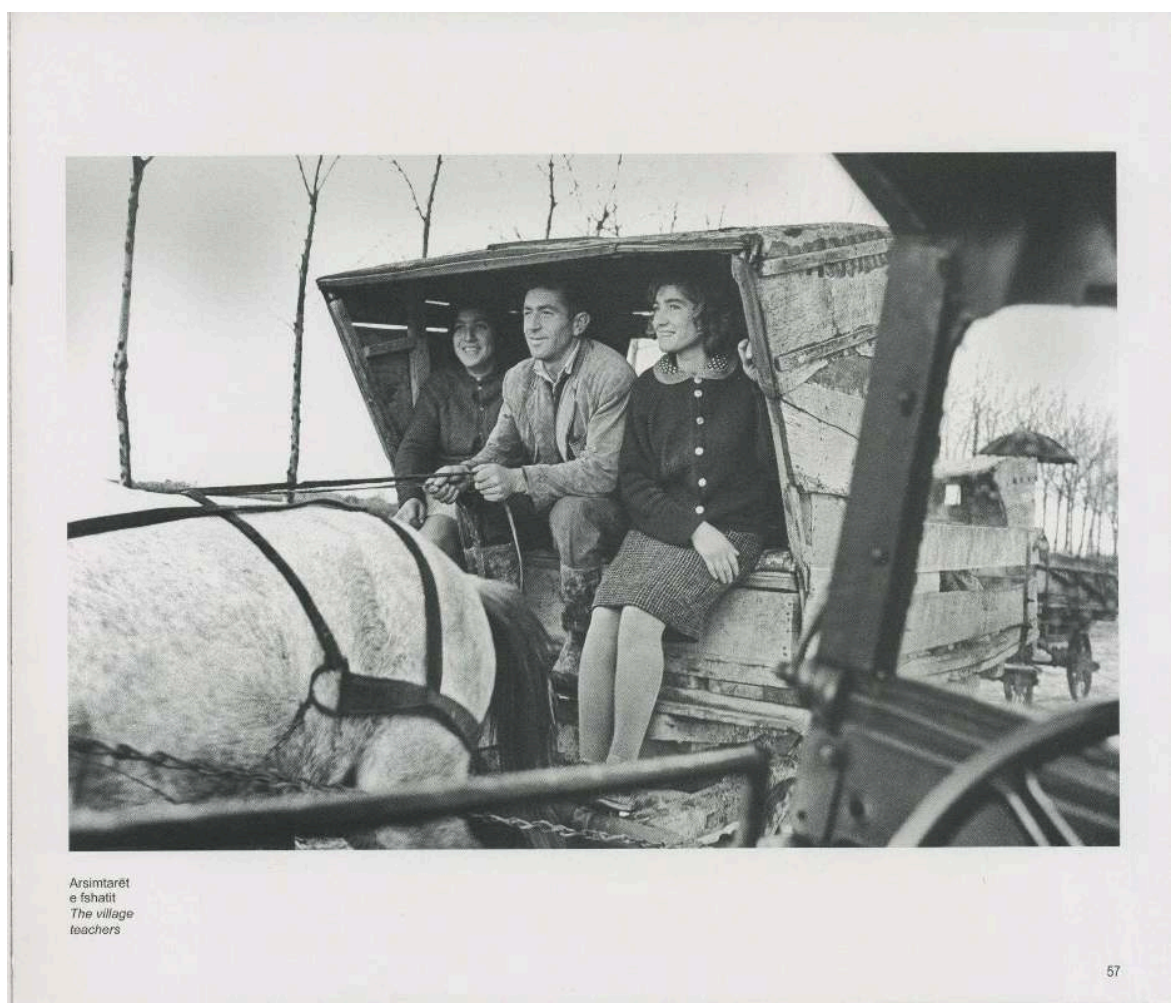

Kumi, 2013, p. 57

41 Enfin, un dernier glissement permet d'éviter la lecture de ces photographies en tant que propagande communiste: c'est le passage par le patriotisme, qu'il soit national, comme chez Petrit Kumi, ou régional, comme dans l'album Dokle. À propos des " actions », Petrit Kumi précisait que la jeunesse était motivée par le patriotisme plus que par l'idéologie communiste; lui-même se définit comme le photographe «de l'Albanie » (për Shqipërinë, littéralement " pour l'Albanie») et insiste sur le fait qu'il travaillait pour son «pays» (vend) et pour son «peuple» (popull), plus que pour un régime politique (p. 248). Dans l'album des époux Dokle, l'horizon patriotique est celui de la région plus que de la nation et c'est à «l'homme de Kukës » (njeriu kuksian) que s'oppose la dictature, c'est lui qui est au centre de l'attention des photographes (p. 20). Plus encore, le chapitre sur les « Témoignages de la richesse ethnographique » insiste sur le fait que la plus grande partie du travail des photographes s'est déroulée avant 1967 et la " guerre contre les coutumes rétrogrades » déclenchée alors par les autorités communistes ${ }^{21}$. Les photographies reproduites dans ce chapitre sont ainsi présentées comme la marque d'une volonté des photographes de «fixer» la "richesse culturelle populaire" (begati kulturore popullore) du district de Kukës et des petites régions (krahinë) qui le composent (p.178). L'intérêt des photographies réside donc, selon l'auteur, dans ce que l'étude de l'ethnographie et du folklore peut y puiser un riche matériau et cet intérêt s'étend, au-delà de la région, à toute l'Albanie. Pourtant, comme l'attestent les banderoles visibles à l'arrière-plan, beaucoup de ces photographies ont été prises à l'occasion d'événements politiques, comme la célébration du quinzième anniversaire de la «libération de la patrie» (1959) ou des festivals folkloriques organisés par les autorités du district (fig. 33). Loin donc de ne montrer que la « richesse folklorique et ethnographique du district», elles témoignent de la mise en 
scène de la tradition par le pouvoir politique, de l'importance de l'image photographique pour les autorités et de la participation des photographes à cette entreprise. La dimension politique de la photographie ethnographique, et de l'ethnographie en général, est cependant passée sous silence dans la nouvelle mise en scène proposée par l'album et le lecteur est invité à n'y voir que le témoignage d'une identité régionale qui perdure jusqu'à aujourd'hui malgré les transformations subies pendant la période communiste. On peut penser que cet effet de distanciation de la photographie est important à la fois pour dédouaner les photographes eux-mêmes et minimiser leur compromission avec les autorités politiques, et pour garantir à leur production une certaine pérennité et une place dans l'histoire de la photographie albanaise.

Fig. 33. «Duo avec tambourin »

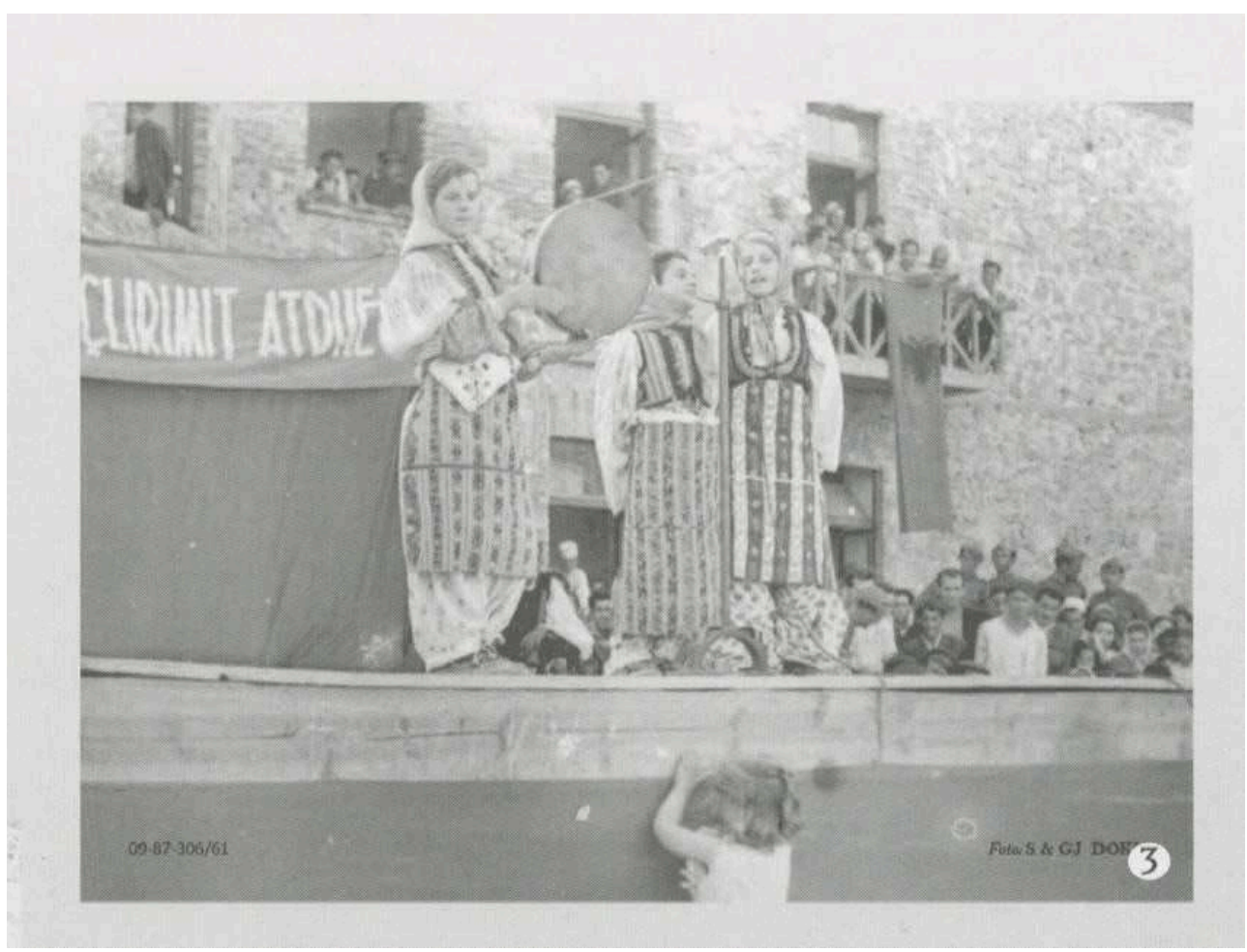

Dokle, 2014, p. 179

\section{Des photographies nostalgiques?}

Troisièmement enfin, ces albums contribuent à la valorisation de la photographie de l'époque communiste par rapport à la photographie actuelle. Cette valorisation s'exprime sous deux formes : il s'agit d'abord de valoriser une technique, celle de la photographie argentique, face à une autre, la photographie numérique, qui jouit d'un engouement massif et tend à renvoyer la première dans le passé. On fait valoir à la fois le côté artisanal et manuel de la première et sa capacité à laisser des objets matériels (négatifs, tirages) qui durent (mais qui, paradoxalement, doivent être numérisés pour la publication). Il s'agit, d'autre part, de valoriser une entreprise documentaire et historique qui s'inscrit dans une tradition. Ces images ont de la valeur parce que, comme l'écrit Petrit Kumi, la période communiste constitue une " histoire différente » 
(p. 248), mais aussi parce qu'elles témoignent de la volonté des photographes de laisser des traces de l'histoire nationale comme ont pu le faire leurs prédécesseurs, les pionniers de la photographie albanaise de la fin du XIX siècle et du début du Xx $\mathrm{X}^{\mathrm{e}}$. Il n'est pas anodin, à cet égard, que les protagonistes des deux albums (auteurs, préfaciers, sponsors) appartiennent à une génération qui a vécu et travaillé pendant la période communiste. Leur entreprise de valorisation et de réhabilitation de la photographie de cette époque doit aussi se comprendre comme une réponse à la disparition des témoins directs de cette histoire et comme une réaction aux représentations les plus partagées de l'Albanie communiste.

Malgré leur objectif affiché de montrer des images de la « réalité » du communisme, ces albums proposent plutôt un discours sur la mémoire du communisme et un cadre, photographique, à cette mémoire. Si la valeur documentaire et historique des images, revendiquée par les auteurs, est incontestable, la mise en scène et la mise en circulation de ces photographies dans le contexte d'aujourd'hui constituent un acte mémoriel et une performance qui disent autre chose que des faits historiques. La façon dont ces albums interviennent dans le présent est complexe car ils mettent en œuvre plusieurs dimensions de la relation entre photographie et mémoire. On y voit en effet la photographie comme volonté de fixer et de retenir une image du présent pour un usage futur. C'est, pour reprendre les termes de Paul Ricœur, la fonction de rétention ${ }^{22}$. Elle est en quelque sorte réactualisée par les deux albums qui, en reproduisant des photographies prises dans l'intention de "fixer » et d'« enregistrer » un certain état, rappellent combien il était important pour le pouvoir politique de garder une trace de son action. Comme nous l'avons suggéré, cette fonction de la photographie relève déjà de la catégorie du performatif puisqu'en cherchant à retenir et prolonger le présent en tant que contenu mémoriel, la photographie est utilisée pour faire advenir la réalité voulue et imaginée par le pouvoir.

La photographie apparait aussi dans les deux albums comme irruption d'une image du passé dans le présent. C'est, pour suivre encore Paul Ricœur, la fonction de reproduction, c'est-à-dire celle de remémoration ou de rappel d'un contenu mémoriel ${ }^{23}$. Les photographies invitent ici les gens qui ont eu l'expérience de la période communiste à se souvenir et à se représenter cette expérience. Le contenu mémoriel ainsi rappelé n'est pas limité à ce qui est visible sur les photographies : l'image agit comme un déclencheur, un "point d'appui extérieur pour le rappe ${ }^{24}$ ", mais ce qui est rappelé n'appartient pas qu'au visuel; la remémoration est une expérience multisensorielle ${ }^{25}$.

Ce type d'album propose donc au public d'aujourd'hui un support avant tout visuel à la remémoration de la période communiste, même si le texte, nous l'avons vu, détermine en grande partie la façon dont les images doivent être regardées. L'accessibilité et le caractère partagé de ce contenu mémoriel, par rapport à l'ensemble de la production photographique conservée, ont pour corollaire le caractère sélectif et limité de ce qui est proposé comme support de remémoration. La publication de ces albums revient donc à donner des cadres photographiques à la mémoire, en agissant sur les conditions du rappel. Enfin, ces albums paraissent aussi à destination d'un public qui n'a pas eu 
l'expérience directe de la période communiste et on peut s'interroger sur la façon dont ils contribuent à former une image du passé communiste pour les générations présentes, comme pour les chercheurs étrangers. La photographie agit moins ici sur la mémoire que sur l'imagination et la croyance. Les pratiques mémorielles que constitue la publication de ces albums peuvent donc avoir des effets à long terme sur l'écriture (au sens large) du passé communiste.

\section{NOTES}

1. Citons par exemple les Memory Days organisés en 2016 et 2017 à Tirana et l'ouverture, en mai 2017, du premier musée consacré à la période communiste à Tirana. Parmi les publications, on peut mentionner l'enquête d'histoire orale de Fabian Kati (KATI Fabian, Formësimi i kujtesës kolektive. Ngjarjet në Dukagjin, Malësinë e Madhe dhe Postribë, 1945-1946 [La formation de la mémoire collective. Les événements de Dukajin, Malësi e Madhe et Postribë, 1945-1946], Tirana, UET Press, 2015 ) et le travail photographique réalisé sur les monuments aux morts (VAN GERVEN OEI Vincent W.J. (dir..), Lapidari, Volume 1: Texts, New York, Punctum Books, 2015).

2. CANDAU Joël, Anthropologie de la mémoire, Paris, Armand Colin, 2005, p. 78-82.

3. Voir, entre autres: HIRSCH Marianne, Family Frames: Photography, Narrative, Postmemory, Cambridge, Mass, Londres, Harvard University Press, 1997 ; KUHN Annette, MCALLISTER Kirsten Emiko (eds), Locating Memory: Photographic Acts, New York, Berghahn Books, 2006 ; KROEs Rob, Photographic Memories. Private Pictures, Public Images, and American History, Hanovre, Londres, University Press of New England, 2007; SHEvchenKo Olga (dir.), Double Exposure: Memory and Photography, New Brunswick, NJ, Transaction Publishers, 2014.

4. SARKISOva Oksana, SHEvchenko Olga, «Soviet Past in Domestic Photography: Events, Evidence, Erasure », dans Olga Shevchenko (dir.), Double Exposure: Memory and Photography, New Brunswick, NJ, Transaction Publishers, 2014, p. 147-174 ; SKOPIN Denis, La photographie de groupe et la politique de la disparition dans la Russie de Staline, Paris, L'Harmattan, 2015.

5. KUMI Petrit, Jeta përmes objektivit. Fotografi \& shënime [La vie à travers l'objectif. Photographies et notes], Tirana, Ideart, 2013.

6. À cette date, en effet, les laboratoires photographiques des différents journaux et magazines sont fermés et les tâches de développement et de tirage sont centralisées au laboratoire de l'ATSH. Voir DE RAPPER Gilles, DURAND Anouck, «Au service du peuple. Coopératives et entreprises de photographes dans l'Albanie communiste », dans Ghislaine Gallenga, Laure Verdon (eds), Penser le service public en Méditerranée. Le prisme des sciences sociales, Paris, Aix-en-Provence, Karthala, Maison méditerranéenne des sciences de l'homme, 2017, p. 219-244.

7. Cette rapide biographie provient des nombreux entretiens que nous avons eus avec Petrit Kumi depuis 2008.

8. DOKLE Nazif, Fotografët Safet e Gjylzade Dokle [Les photographes Safet et Gjylzade Dokle], Tirana, Geer, 2014. Il s'agit, là encore, d'un éditeur généraliste.

9. Ces données biographiques sont tirées du chapitre I : « Les époux photographes ", p. 6-13. À la fin des années 1960, les coopératives d'artisanat au sein desquelles travaillaient les photographes sont transformées en entreprises étatiques. Parallèlement, l'activité de photographe privé est interdite. Voir DE RAPPER, DURAND, « Au service du peuple », op. cit. 
10. Sur l'apparition et le sens de cette métaphore, voir la mise au point de François Brunet: BRUNET François, La photographie : histoire et contre-histoire, Paris, Presses universitaires de France, 2017, p. 28.

11. L'idée d'inconscient optique avancée par Walter Benjamin peut sembler ici pertinente puisque ces photographies, regardées plusieurs décennies après la prise de vue et dans une disposition toute différente, nous montrent bien autre chose que ce que les photographes de l'époque pouvaient voir ou avaient voulu montrer.

12. La place manque ici pour aborder la réception de ces deux albums par le public. Nous ne pourrons que formuler des hypothèses sur l'effet que peuvent avoir ces images sur le spectateur d'aujourd'hui, en gardant à l'esprit que ce qui est donné à voir n'est pas nécessairement vu.

13. RIC@UR Paul, La mémoire, l'histoire, l'oubli, Paris, Seuil, 2000, p. 51.

14. D'après BUDA Aleks (dir.), Fjalor enciklopedik shqiptar [Dictionnaire encyclopédique albanais], Tirana, Akademia e Shkencave e RPS të Shqipërisë, 1985, p. 706.

15. Sur la notion d'icône prise dans ce sens, voir BARTMANSKI Dominik, ALEXANDER Jeffrey C., «Materiality and Meaning in Social Life: Toward an Iconic Turn in Cultural Sociology », dans Jeffrey C. Alexander, Dominik Bartmanski (dir.), Iconic Power. Materiality and Meaning in Social Life, New York, Palgrave Macmillan, 2012, p. 1-12, ici p. 3.

16. Il figure dans l'équipe éditoriale de l'album dirigé par Foto Çami : çAMI Foto, Enver Hoxha, jeta dhe vepra [Enver Hoxha, vie et œuvre], Tirana, Instituti i studimeve marksiste-leniniste pranë KQ të PPSH, 1986.

17. ULQINI Kahreman, Gjurmë të historisë kombëtare në fototekën e Shkodrës [Traces de l'histoire nationale à la photothèque de Shkodër], Tirana, 8 Nëntori, 1982.

18. TODOROV Tzvetan, Mémoire du mal, tentation du bien. Enquête sur le siècle, Paris, Robert Laffont, 2000.

19. Titre d'un documentaire réalisé en 2014 par Matilda Terpollari et diffusé par la chaîne Vizion Plus. Voir : https://www.youtube.com/watch?v=CEkW6sGf-Qc (consulté en mai 2020).

20. VRIONI Qerim, 150 vjet fotografi shqiptare [150 ans de photographie albanaise], Tirana, Milosao, 2009, p. 44.

21. La formule, héritée de la période communiste, renvoie principalement à l'interdiction de la religion et à la fermeture des lieux de culte.

22. RICCEUR, La mémoire, op. cit., p. 37-42.

23. Ibid., p. 42-43.

24. Ibid., p. 46.

25. CANDAU, Anthropologie de la mémoire, op. cit., p. 164.

\section{RÉSUMÉS}

L'examen de deux albums de photographies parus dans les années 2010 à Tirana permet d'analyser le rôle de la photographie de la période communiste dans la fabrication et la transmission d'une mémoire de cette époque. Ces albums constituent un support à la remémoration, combinant image et texte. La sélection et la mise en page des photographies ont pour effet de donner des « cadres photographiques » à la mémoire, en particulier en déplaçant la dimension politique de ces images depuis le paradigme de la construction du socialisme vers celui de la permanence de l'identité nationale albanaise. 
The examination of two albums of photographs published in Tirana in the 2010s allows us to analyze the role of photography of the communist period in the production and transmission of a memory of this period. These albums constitute a support for recollection, combining image and text. The selection and layout of the photographs result in "photographic frames" of memory, in particular by shifting the political dimension of these images from the paradigm of the construction of socialism to that of the permanence of Albanian national identity.

\section{INDEX}

Index géographique : Albanie

Mots-clés : photographie, mémoire, album, communism, Albanie

Keywords : photography, memory, photo book, socialism, Albania

\section{AUTEUR}

\section{GILLES DE RAPPER}

CNRS, Aix-Marseille Université, Idemec, Aix-en-Provence Gilles.DERAPPER[at]idemec.cnrs.fr 